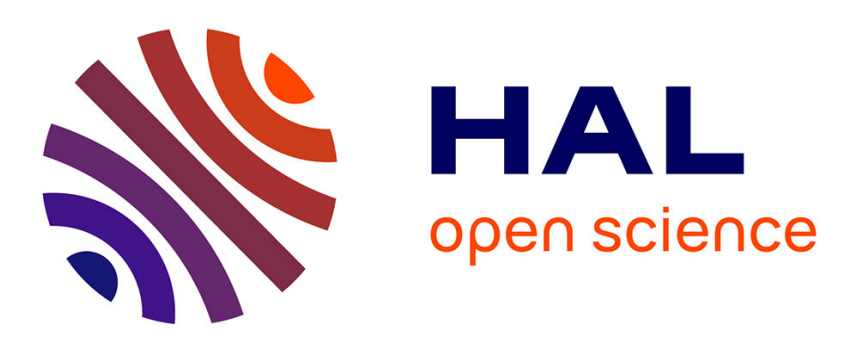

\title{
About the heat sources generated during fatigue crack growth: What consequences on the stress intensity factor?
}

\author{
Zaid Boussattine, Nicolas Ranc, Thierry Palin-Luc
}

\section{To cite this version:}

Zaid Boussattine, Nicolas Ranc, Thierry Palin-Luc. About the heat sources generated during fatigue crack growth: What consequences on the stress intensity factor?. Theoretical and Applied Fracture Mechanics, 2020, 109, pp.1-13. 10.1016/j.tafmec.2020.102704 . hal-02926888

\section{HAL Id: hal-02926888 \\ https://hal.science/hal-02926888}

Submitted on 1 Sep 2020

HAL is a multi-disciplinary open access archive for the deposit and dissemination of scientific research documents, whether they are published or not. The documents may come from teaching and research institutions in France or abroad, or from public or private research centers.
L'archive ouverte pluridisciplinaire HAL, est destinée au dépôt et à la diffusion de documents scientifiques de niveau recherche, publiés ou non, émanant des établissements d'enseignement et de recherche français ou étrangers, des laboratoires publics ou privés. 


\title{
About the heat sources generated during fatigue crack growth: What consequences on the stress intensity factor?
}

\author{
Zaid Boussattine $^{\mathrm{a}}$, Nicolas Ranc ${ }^{\mathrm{a}, *}$, Thierry Palin-Luc ${ }^{\mathrm{b}}$ \\ ${ }^{a}$ Laboratoire PIMM, Arts et Metiers Institute of Technology, CNRS, CNAM, HESAM Université, 151 boulevard de l'Hôpital, 75013 Paris, France \\ ${ }^{\mathrm{b}}$ Arts et Metiers Institute of Technology, University of Bordeaux, CNRS, Bordeaux INP, INRAE, I2M Bordeaux, Esplanade des Arts et Métiers, 33400 Talence, France
}

\section{A R T I C L E I N F O}

\section{Keywords:}

Stress intensity factor

Crack tip cyclic plasticity

Thermoelastic coupling

Intrinsic dissipation

Microplasticity

\begin{abstract}
A B S T R A C T
During cyclic loading of a cracked metallic alloy at room temperature, heat sources are generated and produce a heterogeneous temperature field around the crack tip. Those heat sources are: (i) the thermo-elastic coupling source, (ii) the intrinsic dissipation due to microplasticity in the material, and (iii) the cyclic plasticity dissipated into heat in the reverse cyclic plastic zone (RCPZ) ahead of the crack tip. The thermoelastic source is computed by finite element analysis in agreement with classic linear thermoelasticity theory. The intrinsic dissipation due to microplasticity is experimentally estimated by carrying out self-heating fatigue tests on uncracked specimens, and then approximating its values in the cracked specimens by using self-heating curves. The cyclic plastic strain energy dissipated into heat in the RCPZ is also experimentally quantified by carrying out fatigue crack growth tests and using infrared measurements. The temperature fields, generated by the three types of heat sources, are separately computed by using the linearity of the heat diffusion equation. Afterward, the stress fields, associated with each thermal effect and induced by the material thermal expansion, are computed by considering the hypothesis of the linear elastic fracture mechanics (LEFM). Thus, the mode I stress intensity factor is calculated by taking into account the thermal effect associated with each heat source. The consequences on $K, \Delta K$ and $R_{K}=K_{\min } / K_{\max }$ are discussed. It is shown that the heat sources do not modify significantly $\Delta K$, but the modification of $R_{K}$ can be significant since the effects are proportional to the loading frequency.
\end{abstract}

\section{Introduction}

In recent decades, the development of fatigue machines has led to an increase in the loading frequency in order to characterize the fatigue behavior of materials more quickly. These frequencies can nowadays reach $1000 \mathrm{~Hz}$ for hydraulic fatigue testing machines and several tens of kilohertz for ultrasonic ones. Moreover, it is rather common to find structures (turbine blade in a turbojet engine, turbopump in a rocket engine...) which are loaded at very high frequencies. The increase in the frequency generates self-heating of the loaded material which can be significant and can influence the fatigue behavior of the material and in particular the crack propagation.

The stress intensity factor (SIF) plays a major role in studying crack propagation. It was developed in the mid-1950s by Irwin [13]. Based on Westergaard's plane problem solution for the stress field surrounding the tip of a finite crack in an infinite medium [35], Irwin defined the SIF, denoted by $K$, as a mechanical parameter characterizing the state of the stress field at the crack tip. Several methods have been developed to calculate the SIF for various geometries of specimens, such as asymptotic approximations [17,12,32], weight functions [6,30], Green's functions [23,3], J-integral method [29,8], and finite element methods $[16,31]$. However, one basic assumption to calculate the SIF needs to be held, it is the small scale yielding assumption [23,14,28]. Indeed, a plastic zone develops at the tip of the crack during crack loading, and as the applied load increases, the size of this plastic zone increases too until the crack grows and the elastically loaded material behind the crack tip unloads. When this plastic zone at the crack tip is very small compared with both the region where the material remains elastic and the crack length, the situation is called small scale yielding. Rice showed [27] that unloading a crack after a loading phase creates a reversed flow plastic zone at the crack tip which is included in the plastic zone created after the first loading phase. Consequently, the plastic loading and unloading cycle at the crack tip leads to a reverse cyclic plastic zone (RCPZ) where the cyclic plasticity is mostly converted into heat $[11,33]$. Stüwe and Pippan showed in [24] that the plastic work dissipated into heat in the RCPZ verifies a fourth power

\footnotetext{
* Corresponding author.

E-mail address: nicolas.ranc@ensam.eu (N. Ranc).

URL: https://pimm.artsetmetiers.fr/user/57 (N. Ranc).
} 


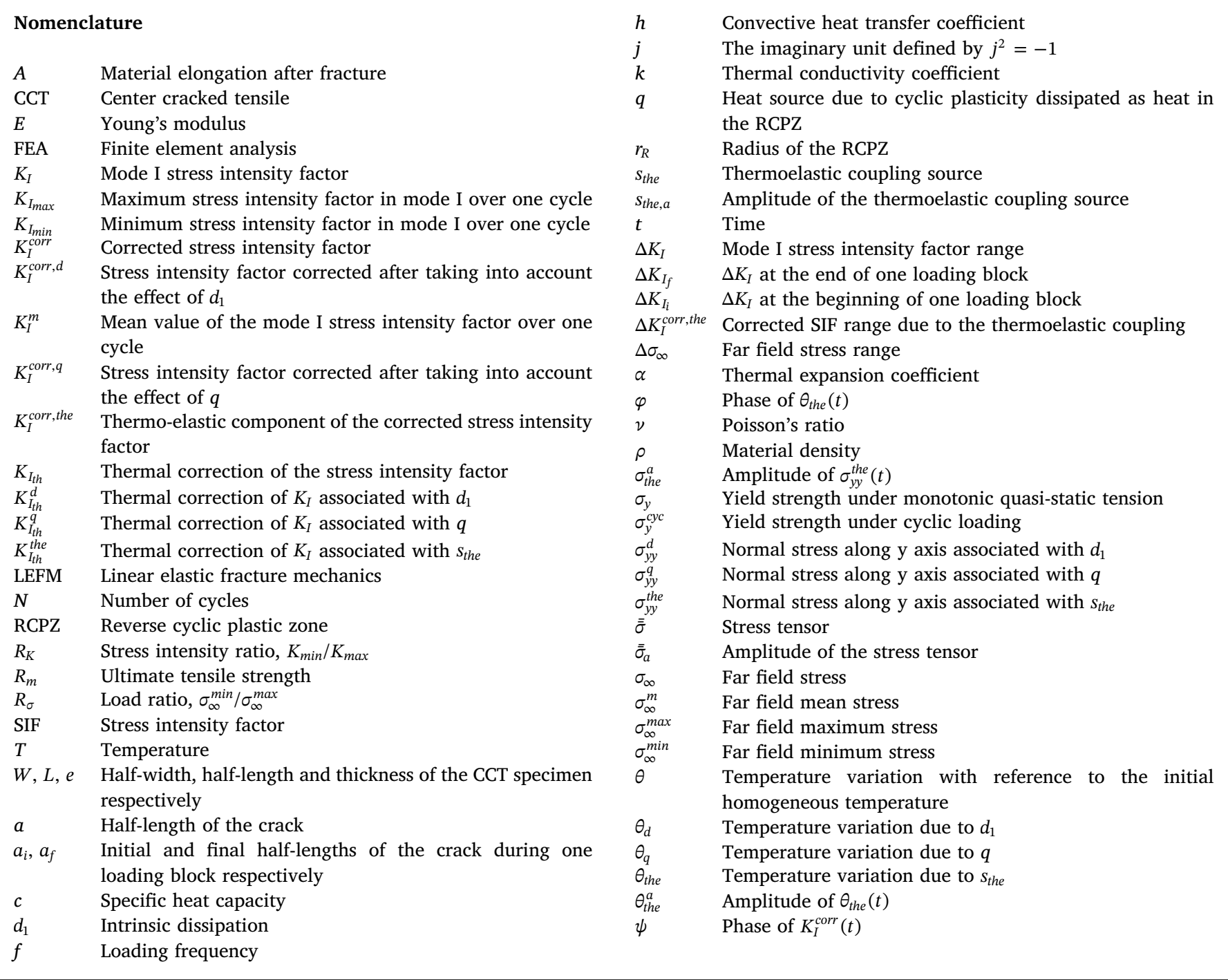

law with the applied SIF range, $\Delta K$. However, their study did not cover the consequences of the dissipated cyclic plastic work at the crack tip, on the SIF, $K$.

The classical fatigue crack growth tests carried out at room temperature have always been considered as isothermal, which means that there is no temperature change in the material during the tests. The SIF is then calculated in a classical way under the assumption of small scale yielding, with no thermal effects taken into consideration. But, by cycling a cracked specimen, the heat produced in the RCPZ creates a heterogeneous temperature field around the crack tip as shown in $[2,15,25,26,22]$. Therefore, the assumption of isothermal fatigue crack growth tests is called into question. Furthermore, the heterogeneous temperature field created at the crack tip leads to a heterogeneous stress field due to thermal expansion of the material. As a result, the global stress field over the crack is modified, which consequently impacts the SIF, $K$. This impact was first studied in [25] by using an analytic development of a theoretical problem involving thermomechanical stresses in an infinite plate with a semi-infinite through crack. They first established an analytic relationship between the SIF and the heat source due to cyclic plasticity dissipated into heat in the RCPZ. Then, they concluded that the cyclic plastic dissipation at the crack tip modifies the SIF as well as the ratio $R_{K}=K_{\min } / K_{\max }$, and does not modify the SIF range, $\Delta K$. Later on, the effect of the cyclic plastic dissipation on $K$ in the case of a long propagating fatigue crack in a finite center-cracked specimen is studied in [26]. They carried out infrared measurements of the temperature field created at the crack tip during cyclic loading, and proposed an approach to quantify the cyclic plasticity dissipated into heat in the RCPZ. Then, they found that the resulting effect decreases the value of the SIF $K$. However, the impact on $K$ related to other possible thermal effects which are produced during fatigue crack growth tests was not studied.

This paper comes to show that besides the cyclic plasticity dissipated into heat in the RCPZ, denoted later by $q$, two other heat sources are produced during fatigue crack growth: (i) the thermoelastic source, denoted by $s_{\text {the }}$, which is related to the material thermoelastic behavior induced by the dependence between the stress tensor, the strain tensor, and the temperature $([10,34])$. It fluctuates over time and is proportional to the hydrostatic part of the stress tensor response of the material. Its associated energy vanishes at the end of each complete load cycle; and (ii) the intrinsic dissipation due to microplasticity, denoted by $d_{1}$, which results from the self-heating phenomena induced by the dissipation into heat of the cyclic plasticity, at the grain scale, occurring in the material outside the RCPZ. It is an intrinsic property of the material behavior and depends on the local stress amplitude, the applied loading frequency and the applied loading ratio, $[20,9]$.

The aim of this study is to verify if the heat sources in question have consequences on the SIF, $K(t)$, the SIF range, $\Delta K=K_{\max }-K_{\min }$, and the stress intensity ratio, $R_{K}=K_{\min } / K_{\max }$, in the case of a long mode I propagating fatigue crack. In total, three heat sources are considered in this paper, $s_{\text {the }}, d_{1}$, and $q$. $s_{\text {the }}$ is a volume power, $d_{1}$ is a volume power 
averaged over one load cycle, and $q$ is a power per unit length of the crack front averaged over one load cycle. It must be noted that the two dissipative sources, $d_{1}$ and $q$, both originate from cyclic plasticity, but at different scales: $q$ is defined at the macro-scale, while $d_{1}$ is defined at the micro-scale (or grain scale). Moreover, $q$ and $d_{1}$ are positive and increase after every loading cycle to reach constant values after a few cycles over the duration of the applied load block (about ten cycles over 25000 at loading frequencies around $100 \mathrm{~Hz}$ ). In this study for sake of simplicity, both $d_{1}$ and $q$ are assumed to be time-independent during one applied load block.

A specific methodology has been proposed in this work. It is first described. Secondly, the quantification of the three heat sources, which are the key inputs of this study, is presented. Finally, the consequences of the three types of thermal effects, on $K_{I}(t), \Delta K_{I}$, and $R_{K}$, are discussed.

\section{Methodology and assumptions}

During classic fatigue crack growth tests at room temperature, the mode I fatigue crack propagation is governed by $K_{I}(t), \Delta K_{I}$, and $R_{K}$. Let, $K_{I t h}(t)$, be the thermal correction of the SIF, generated by the thermal effects introduced before. The main problem, where the mechanical and thermal effects are coupled, can be decomposed into two problems according to the LEFM hypothesis and by assuming no crack closure effect for sake of simplicity. Fig. 1 illustrates this decomposition with a two-dimensional center-cracked tensile (CCT) specimen.

The first problem (i) of the decomposition is purely mechanical. Under the applied sinusoidal loading, $\sigma_{\infty}(t)$, with the loading ratio $R_{\sigma}=\sigma_{\infty}^{\min } / \sigma_{\infty}^{\max }$, the associated SIF, $K_{I}(t)$, can be written as:

$K_{I}(t)=\frac{\Delta K_{I}}{2} \sin (2 \pi f t)+K_{I}^{m}$,

$K_{I}^{m}=\frac{\Delta K_{I}}{2}\left(\frac{1+R_{\sigma}}{1-R_{\sigma}}\right)$

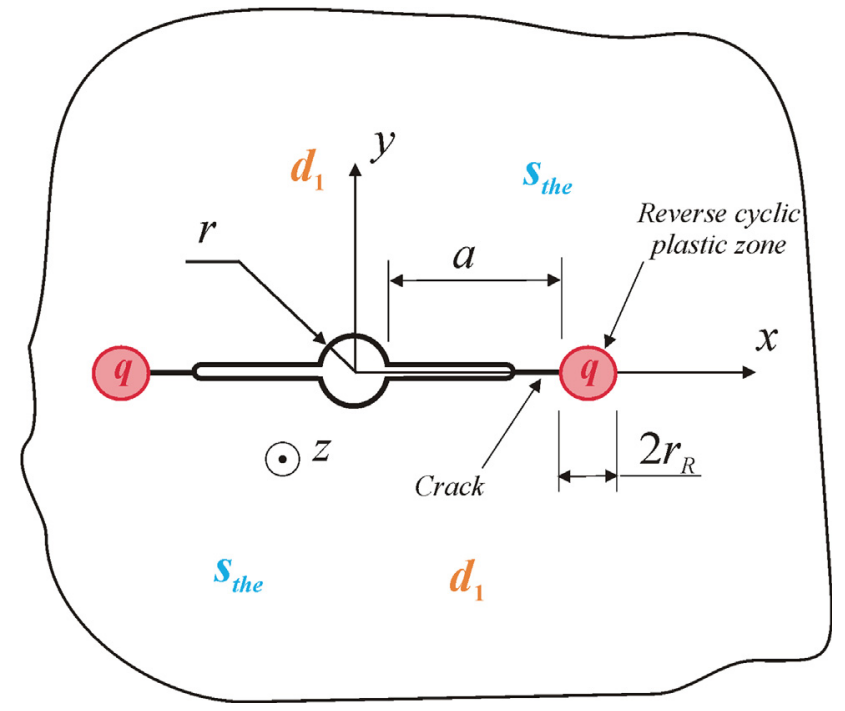

Fig. 2. A schematic fatigue crack model showing the position of the $x, y$ coordinates used in Eq. (5).

where $f$ is the loading frequency, $t$ is time, $K_{I}^{m}$ is the mode I mean value of the SIF. And the stress intensity ratio can be expressed as:

$R_{K}=R_{\sigma}$.

The mode I SIF is calculated with the following relation proposed by [32]

$K_{I}(t)=\sigma_{\infty}(t) \frac{\sqrt{\pi a}}{2}\left(3-\frac{a}{a+r}\right)\left(1+1.243\left(1-\frac{a}{a+r}\right)^{3}\right)$,

with $a$ the half-length of the crack and $r$ the radius of the central hole (Fig. 2).

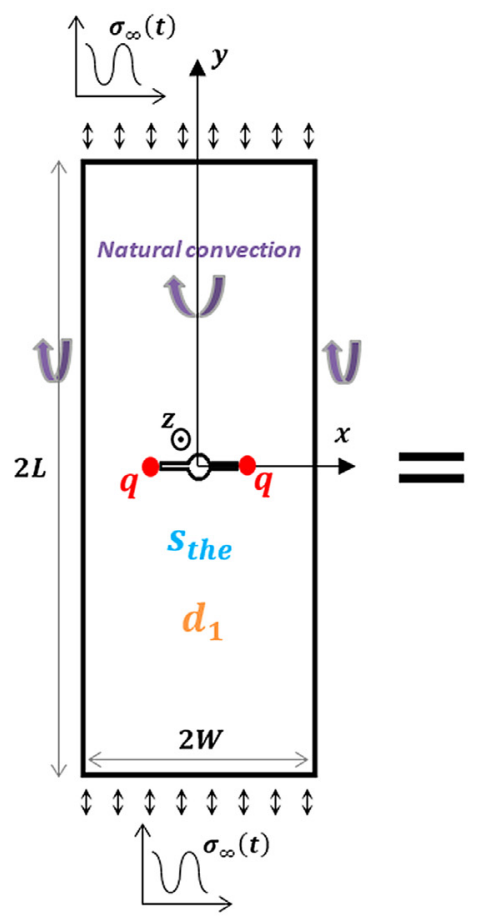

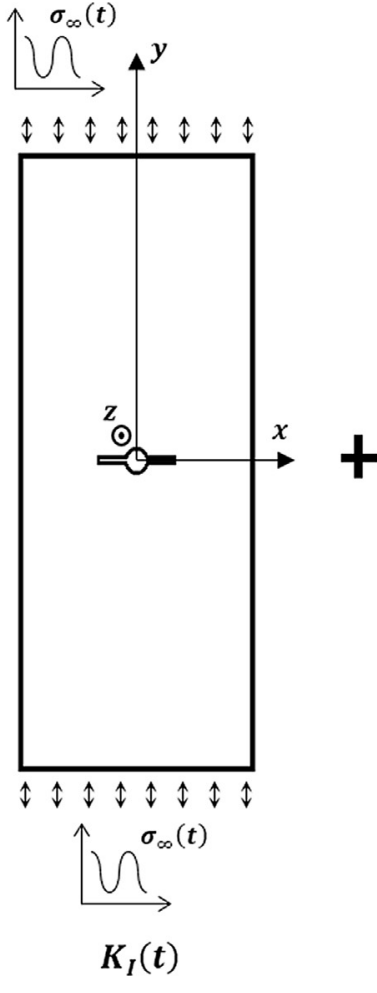

(i)

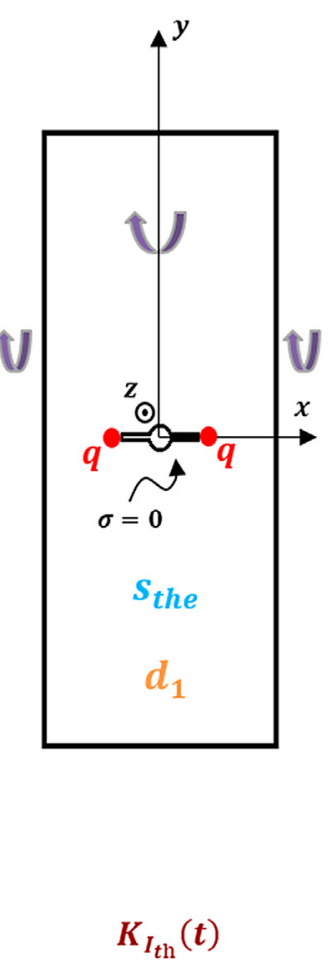

(ii)

Fig. 1. Decomposition of the main problem in two problems (i) and (ii), according to the LEFM hypothesis. 
The second problem (ii) is a thermo-mechanical problem. It is related to the thermal effects due to the heat sources $s_{\text {the }}, d_{1}$, and $q$. First, the three heat sources are quantified. Afterward, the linearity of the heat diffusion problem enables to separately compute the temperature variation fields, $\theta_{\text {the }}, \theta_{d}$, and $\theta_{q}$ (with respect to a reference homogeneous temperature field, $T_{0}$ ) respectively generated by the heat sources $s_{t h e}, d_{1}$, and $q$. One can note that this is possible since the temperature variations are small compared to the reference temperature. Indeed, the material temperature variation during cyclic loading is, $\theta=\theta_{\text {the }}+\theta_{d}+\theta_{q}$. Then, within the LEFM, each temperature variation field contributes to the thermal expansion of the material and consequently creates an associated stress field. Therefore, each thermal stress field induces a thermal correction on the SIF computed by using the Green's function technique [7]. This is defined by Eq. (5).

$K_{I_{t h}}(t)=2 \sqrt{\frac{a}{\pi}} \int_{r}^{a+r} \frac{\sigma_{y y}(x, 0, t)}{\sqrt{a^{2}-(x-r)^{2}}} \mathrm{~d} x$,

where the integrand is defined for the range, $x \in[r, a+r]$, and $a$ and $r$ are respectively the half-crack length and the radius of the central hole as illustrated in Fig. 2. For simplification, the RCPZ is modeled by a disc located ahead of the crack tip (Fig. 2) whose radius, $r_{R}$, is estimated under the plane stress hypothesis by Eq. (6), [28].

$r_{R}=\frac{1}{8 \pi}\left(\frac{\Delta K_{I}}{\sigma_{y}^{c y c}}\right)^{2}$.

In Eq. (5), $\sigma_{y y}(x, 0, t)$ is defined as the normal stress field toward $y$ axis generated by thermal expansion such that the condition of uncracked body is applied. That is why, the thermomechanical problem (ii) on the right in Fig. 1 is decomposed, within the LEFM and the assumption of no crack closure effect, into two sub-problems satisfying the superposition principle (Fig. 3). For simplifying the notation, $\sigma_{y y}(x, 0, t)$ is denoted by $\sigma_{y y}(x, t)$ in the following.

The first sub-problem of Fig. 3 is the uncracked CCT specimen where the thermomechanical stress field associated with each heat source is computed. This sub-problem is solved such that only the elastic domain is considered and the boundary condition over the RCPZ contour is that the radial stress is null as proposed in $[25,26]$. Indeed, with alternating plasticity in the RCPZ, the mean stress tends to zero.

All the calculations have been carried out by a home-made Matlab code using finite element analysis (FEA) based on two-dimensional quadratic meshing as the problem deals with singularities. This homemade finite element code allows to take into account convection losses on the element surface. For each computation, the time and space discretizations have been chosen to have no significant effect on the

results.

\section{Material and specimen geometry}

CCT specimens are used in this study to carry out fatigue crack growth tests. They are made of C40 steel. This is a medium carbon steel with the physical properties given in Table 1 , where $E$ is the Young's modulus, $v$ is the Poisson's ratio, $\sigma_{y}$ is the yield strength under quasistatic monotonic tension, $\sigma_{y}^{c y c}$ is the cyclic yield strength, $R_{m}$ is the ultimate tensile strength, $A$ is the material elongation after fracture, $\rho$ is the material density, $\alpha$ is the thermal expansion coefficient, $k$ is the thermal conductivity coefficient, and $c$ is the specific heat capacity. The CCT specimens are designed according to the ASTM Standard E647, [1]. The geometry is illustrated in Fig. 4.

It should be mentioned that in the calculations presented in this paper, the material is supposed homogeneous and isotropic with a linear-thermoelastic mechanical behavior.

\section{Quantification of the heat sources and computation of the resulting temperature fields}

This step consists in quantifying the heat sources, $s_{\text {the }}, d_{1}$, and $q$, as well as computing their associated temperature variation fields, $\theta_{\text {the }}, \theta_{d}$, and $\theta_{q}$. It should be noted that the thickness of the CCT specimens (Fig. 4) is very small compared to its length and width. Moreover, during fatigue tests, since the CCT specimens respect ASTM standard requirements, it is reasonable to assume that the load is uniformly applied at its upper and lower boundaries by forces acting parallel to its plane and uniformly distributed through the thickness. Having considered these conditions, the hypothesis of plane stresses is adopted in order to simplify the problem and reduce the calculation time.

Furthermore, due to the symmetries of the CCT specimen geometry, a two-dimensional model of one-fourth of the specimen is considered. The geometry of this quarter model is presented in Fig. 5 where $a_{i}$ and $a_{f}$ are the initial half crack length at respectively the beginning and the end of the sinusoidal load block (the same with $\Delta K_{I_{i}}$ and $\Delta K_{I_{f}}$ ).

An example of loading configuration is considered all along this paper in order to highlight the quantification of the heat sources as well as their associated temperature variation fields. It corresponds to the conditions of a real loading applied during fatigue crack growth tests which allowed to quantify the heat source, $q$. These conditions are given in Table 2.
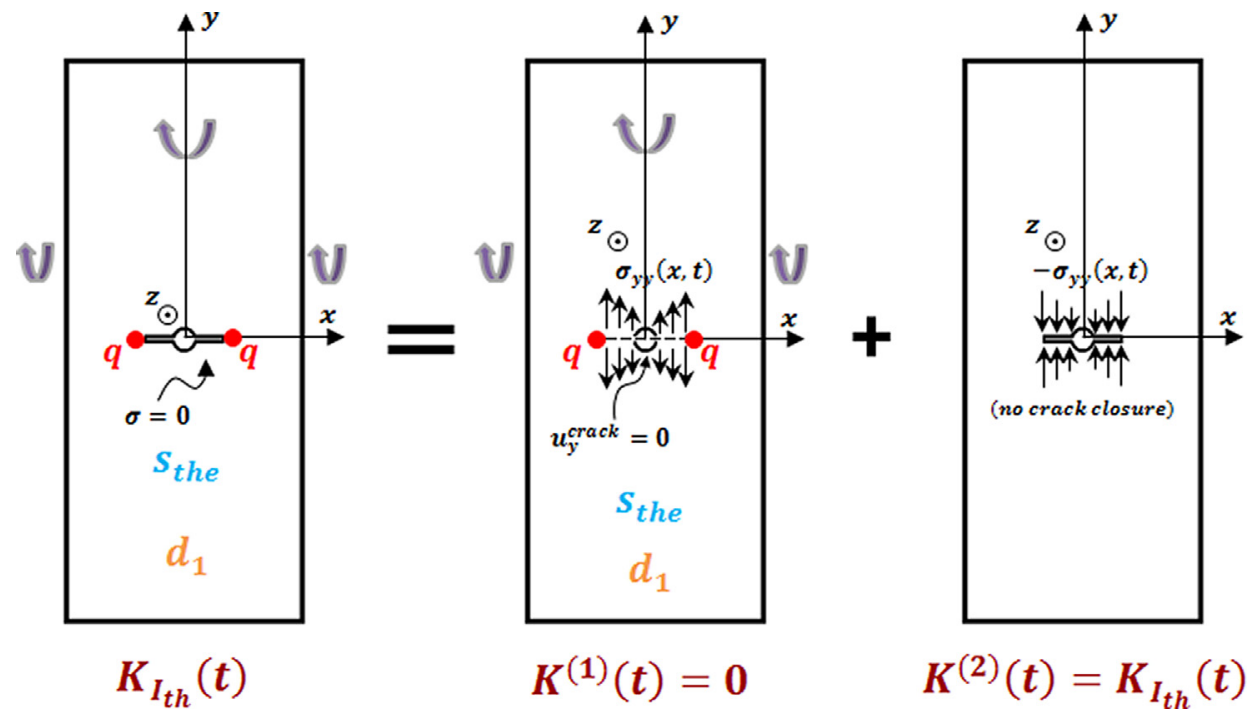

Fig. 3. Decomposition of the thermo-mechanical problem (ii) into two sub-problems. 
Table 1

Physical properties of C40 steel.

\begin{tabular}{|c|c|c|c|c|c|c|c|c|c|}
\hline$E$ & $v$ & $\sigma_{y}$ & $\sigma_{y}^{c y c .}$ & $R_{m}$ & $A$ & $\rho$ & $\alpha$ & $k$ & $c$ \\
\hline $\mathrm{GPa}$ & & $\mathrm{MPa}$ & $\mathrm{MPa}$ & $\mathrm{MPa}$ & $\%$ & $\mathrm{~kg} \cdot \mathrm{m}^{-3}$ & $\mathrm{~K}^{-1}$ & $\mathrm{~W} \cdot \mathrm{K}^{-1} \cdot \mathrm{m}^{-1}$ & $\mathrm{~J} . \mathrm{K}^{-1} \cdot \mathrm{kg}^{-1}$ \\
\hline 210 & 0.3 & 340 & 200 & 600 & 16 & 7568 & $1.2 \times 10^{-5}$ & 52 & 460 \\
\hline
\end{tabular}

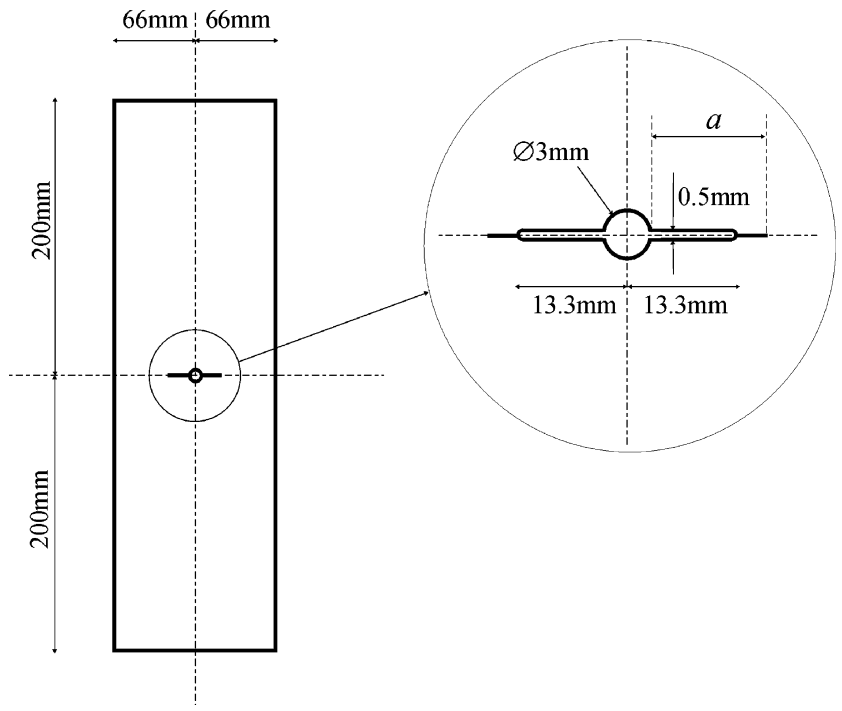

Fig. 4. Geometry of the CCT specimen (the thickness is $4 \mathrm{~mm}$ ).



Fig. 5. Geometry of the quarter model of the CCT specimen.

Table 2

Example of loading configuration considered for quantifying the thermal effects.

\begin{tabular}{|c|c|c|c|c|c|c|}
\hline$R_{K}$ & $\begin{array}{c}f \\
\mathrm{~Hz}\end{array}$ & $\begin{array}{c}a_{i} \\
\mathrm{~mm}\end{array}$ & $\begin{array}{c}a_{f} \\
\mathrm{~mm}\end{array}$ & $\begin{array}{c}\Delta K_{I_{i}} \\
\mathrm{MPa} . \sqrt{\mathrm{m}}\end{array}$ & $\begin{array}{c}\Delta K_{I_{f}} \\
\mathrm{MPa} \cdot \sqrt{\mathrm{m}}\end{array}$ & $\begin{array}{l}T_{0} \\
{ }^{\circ} \mathrm{C}\end{array}$ \\
\hline 0.1 & 98.6 & 25.6 & 29.8 & 26.0 & 28.0 & 20 \\
\hline
\end{tabular}

\subsection{The thermoelastic source}

Since the theory of thermoelasticity is very well established for metallic alloys $[10,34]$, the field of thermoelastic source, $s_{\text {the }}$, has been numerically computed by developing the equations of linear thermoelasticity. Indeed, by assuming linear thermoelasticity and isotropy of responses in both the deformation and thermal expansion phenomena, as well as small temperature variations, $\theta=T-T_{0}$, [19], the thermoelastic source is defined by Eq. (7).

$S_{\text {the }}=-\alpha T_{0} \operatorname{Tr}(\dot{\bar{\sigma}})$,

where $\operatorname{Tr}(\dot{\bar{\sigma}})$ is the time derivative of the stress tensor trace associated with the material stress response resulting from the applied mechanical loading. Since the applied loading is sinusoidal, the resulting stress response in the CCT specimen is also sinusoidal and can be expressed as: $\overline{\bar{\sigma}}(x, y, t)=\overline{\bar{\sigma}}_{a}(x, y) \cdot \sin (2 \pi f t)+\overline{\bar{\sigma}}_{m}(x, y)$ where $\overline{\bar{\sigma}}_{a}$ is the stress tensor amplitude and $\overline{\bar{\sigma}}_{m}(x, y)$ is the mean stress tensor. The thermoelastic source can then be explicitly expressed according to Eqs. (8) and (9).

$s_{\text {the }}(x, y, t)=s_{\text {the }}^{a}(x, y) \sin \left(2 \pi f t-\frac{\pi}{2}\right)$,

where

$s_{\text {the }}^{a}(x, y)=2 \pi f \alpha T_{0} \operatorname{Tr}\left(\overline{\bar{\sigma}}_{\mathrm{a}}(x, y)\right)$,

is the thermoelastic source amplitude. It should be pointed out that the mean stress tensor is not involved in defining the thermoelastic source because the applied mean stress is time-independent and then disappears in the time derivative of the stress tensor trace (Eq. (7)). Thus, according to Eq. (9), after computing the trace of the stress field amplitude associated with the applied mechanical loading using a FEA method, the field of thermoelastic source amplitude is computed. This is depicted in Fig. 6 where it can be seen that the field of the thermoelastic source amplitude is singular at the crack tip because the stress response, and then the trace of the stress response, are singular in the same region.

Having computed the field of the thermoelastic source amplitude, it is now possible to compute the resulting thermoelastic temperature variation field. For this purpose, a thermal problem needs to be defined. First, it is assumed that the computed two-dimensional field of thermoelastic sources is representative of what happens throughout the CCT specimen thickness since it results from the stress tensor which is calculated under the assumption of plane stresses. In addition, the resulting thermoelastic temperature variation field is also supposed to be homogeneous over the thickness. With these assumptions, the thermal problem enabling to calculate the thermoelastic temperature field can be modeled by the following two-dimensional heat diffusion problem:

$\rho c \dot{\theta}_{\text {the }}-k\left(\frac{\partial^{2} \theta_{\text {the }}}{\partial x^{2}}+\frac{\partial^{2} \theta_{\text {the }}}{\partial y^{2}}\right)+\frac{2 h}{e} \theta_{\text {the }}=s_{\text {the }}(x, y, t)$,

$\theta_{\text {the }}(x, y, t=0)=0$

$\left.k \frac{\partial \theta_{\text {the }}}{\partial x}\right|_{x= \pm W}=h \theta_{\text {the }}(x= \pm W, y, t)$

$\left.k \frac{\partial \theta_{\text {the }}}{\partial y}\right|_{y= \pm L}=h \theta_{\text {the }}(x, y= \pm L, t)$

where the term, $\frac{2 h}{e} \theta_{\text {the }}$, results from averaging the temperature over the CCT specimen thickness, $e$, [9]. This term represents the heat exchange by convection with air which occurs over the upper and lower surfaces of the CCT specimen. The material density, $\rho$, the specific heat, $c$, and the thermal conductivity coefficient, $k$, are material constants. They are 


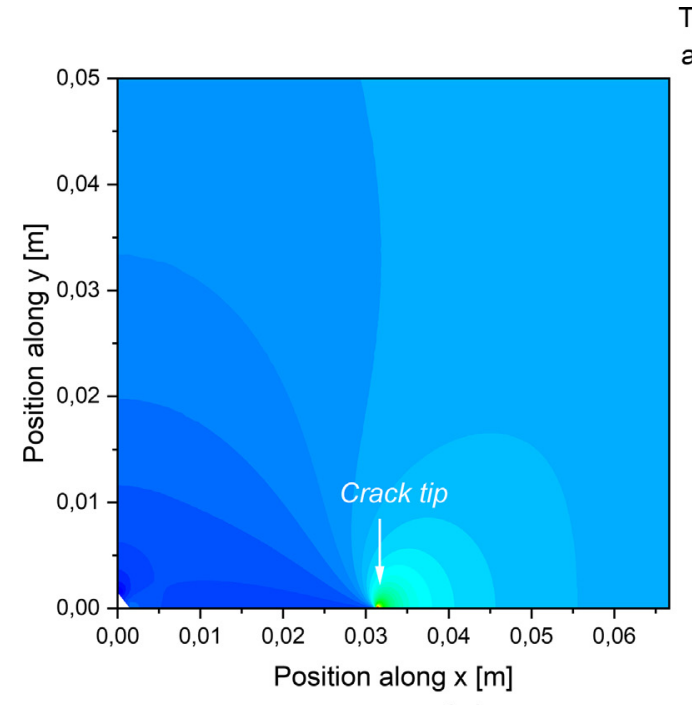

(a)

Thermoelastic source amplitude $s_{\text {the }}^{a}\left[\mathrm{~W} / \mathrm{m}^{3}\right]$

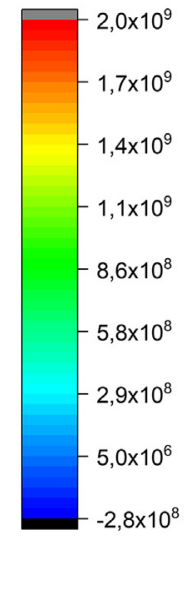


(a) Zoom near the crack tip region, (b) evolution of $s_{\text {the }}^{a}$ along $x$-axis.

assumed to be independent of the material internal state. Natural convection in air is considered as a thermal boundary condition applied around the CCT specimen with, $h=10 \mathrm{~W} . \mathrm{m}^{-2} . \mathrm{K}^{-1}$, as the typical value for natural convection in air.

Since the thermoelasic source is sinusoidal (Eq. (8)), the solution of the heat diffusion Eq. (10) is also sinusoidal. Thus, $\theta_{\text {the }}$ can be written as follows:

$\theta_{\text {the }}(x, y, t)=\theta_{\text {the }}^{a}(x, y) \sin (2 \pi f t+\varphi(x, y))$,

where $\theta_{\text {the }}^{a}$ is the amplitude of the thermoelastic temperature variation field, and $\varphi$ denotes the phase shift between the thermoelastic temperature and the mechanical cyclic loading. The computations of the amplitude, $\theta_{\text {the }}^{a}$, and the phase, $\varphi$, are carried out by solving the heat diffusion Eq. (10) by FEA.

Fig. 7 depicts the amplitude of the thermoelastic temperature variation field, $\theta_{\text {the }}^{a}$, as well as its evolution along $x$ axis. It can be seen that $\theta_{\text {the }}^{a}$ is singular at the crack tip, which results from the singularity of the

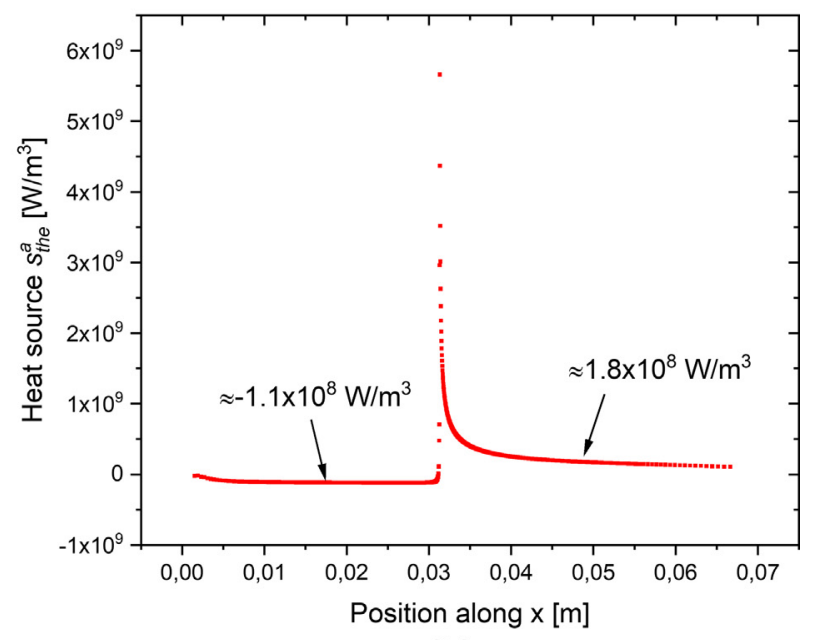

(b)



(a) thermoelastic source amplitude (Fig. 6).

Fig. 8 plots the phase shift, $\varphi$, along $x$ axis. It can be observed that $\varphi$ changes at the crack tip because of important heat losses due to conduction occurring in the same region. Note that for sake of simplicity convective losses were not modeled between the crack lips.

\subsection{The intrinsic dissipation due to microplasticity outside the RCPZ}

The intrinsic dissipation due to microplasticity outside the RCPZ, $d_{1}$, has been experimentally quantified. Classic self-heating fatigue tests were carried out at room temperature with non-cracked smooth specimens $[21,18]$ in order to establish the self-heating curve of the C40 steel. This allowed us to estimate the values of $d_{1}$ at each point (elementary volume) of the CCT specimen from the self-heating curve.

The geometry of the non-cracked smooth specimens is illustrated in Fig. 9. The self-heating fatigue tests with these specimens were carried out by using a resonant fatigue machine (or Vibrophore) with a load

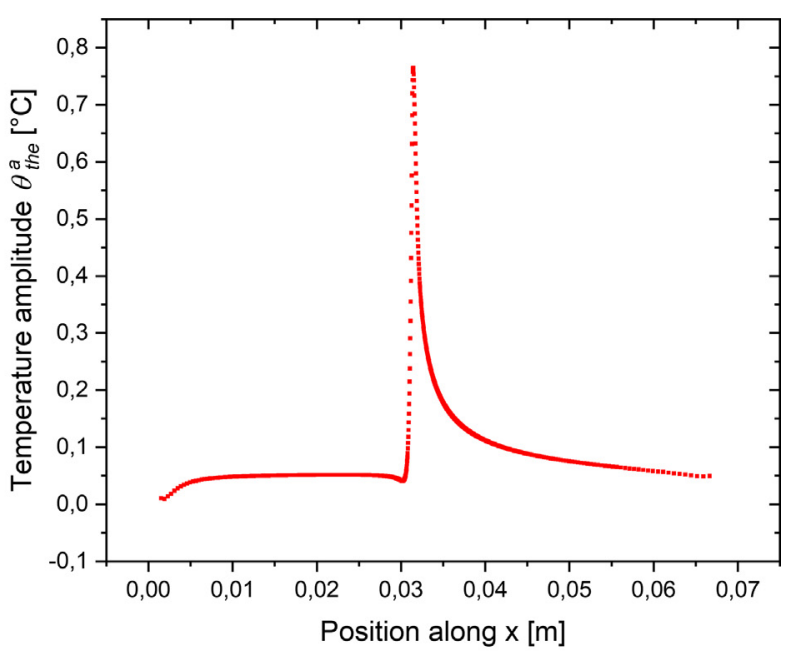

(b)


$a_{f}=29.8 \mathrm{~mm}, f=98.6 \mathrm{~Hz}, \Delta K_{I_{f}}=28.0 \mathrm{MPa} . \sqrt{\mathrm{m}}, R_{K}=0.1$ and $T_{0}=20^{\circ} \mathrm{C}$, (a) Zoom near the crack tip region, (b) evolution of $\theta_{\text {the }}^{a}$ along $x$-axis. 


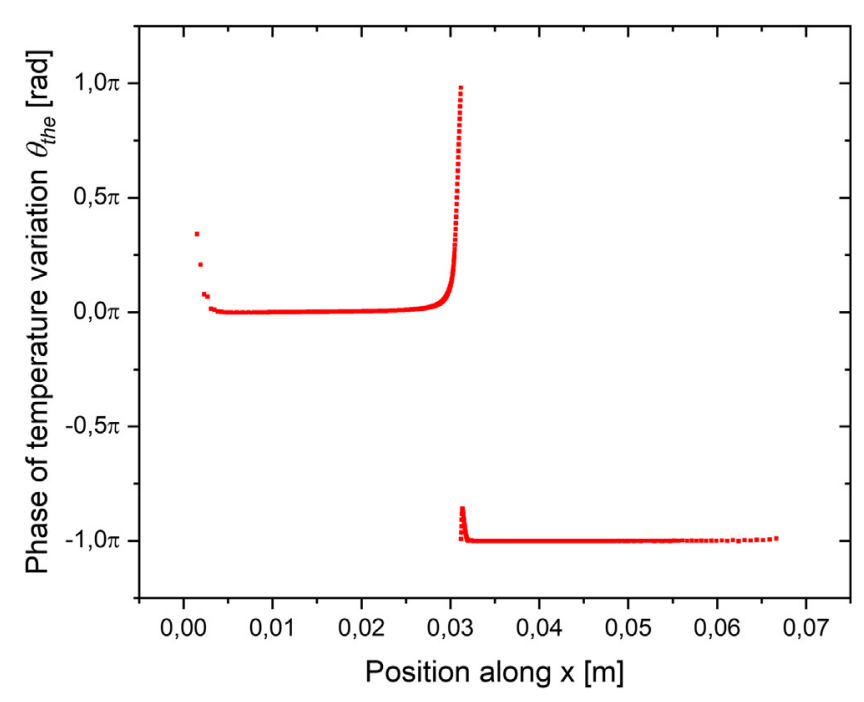

Fig. 8. Evolution of the phase shift $\varphi$ along $x$ axis.

capacity of $150 \mathrm{kN}$ peak to peak. It has mechanical grips fixing the specimen at its extremities. This is an advantage compared with hydraulic grips used in servohydraulic testing machines which heat up because of pressurized oil and may generate additional heating in the specimen during cyclic loading. Therefore, by the use of mechanical grips, the specimen heating in the grips is neglected.

During these tests, an infrared camera measured and recorded the temperature evolution on the non-cracked specimen surface. The camera model used in this experimental investigation is FLIR SC7000 MWR. The measuring range of the camera has been chosen between $5{ }^{\circ} \mathrm{C}$ and $300{ }^{\circ} \mathrm{C}$, and the frequency acquisition and the integration time are respectively $5 \mathrm{~Hz}$ and $600 \mu \mathrm{s}$. In order to enhance the temperature measurements, the surface of the specimen was covered by a thin layer of mat black paint used as a coating to increase the emissivity of the material surface and avoid reflections from the environment. The infrared camera image resolution has been configured on $320 \times 256$ pixels $(1 \mathrm{~mm} \approx 5 \mathrm{px})$ in order to observe the whole heating central gauge area.

For the experimental loading conditions, series of load blocks are applied (Fig. 10). They have been performed under sinusoidal loadcontrol at room temperature around $20^{\circ} \mathrm{C}$, at a load ratio, $R_{\sigma}=0.1$, and applied stress amplitudes, $20 \leqslant \frac{\Delta \sigma}{2} \leqslant 140 \mathrm{MPa}$. The loading frequencies are in the range $[87 \mathrm{~Hz} ; 93 \mathrm{~Hz}]$. When the temperature measured on the specimen surface reaches the stabilized regime, the self-heating fatigue test is stopped.

The technique used in this study to determine the intrinsic dissipation, $d_{1}$, with the non-cracked specimens is described in [5] and can be explicitly expressed by the equation:

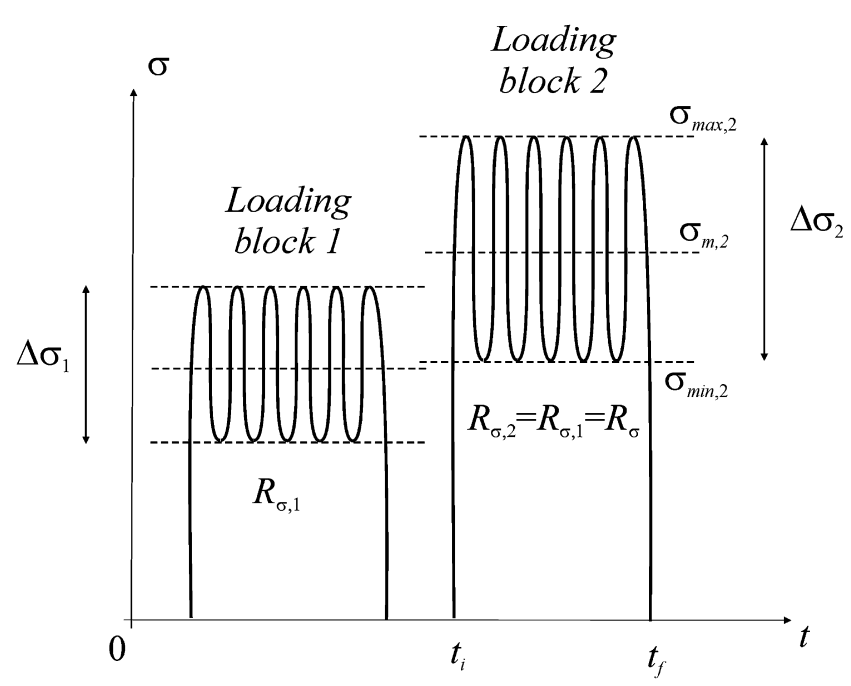

Fig. 10. Schematic illustration of the loading in blocks with constant loading ratio, $R_{\sigma}$.

$d_{1}=\frac{\rho c}{\tau} \bar{\theta}_{d}^{s t a}$,

where $\bar{\theta}_{d}^{\text {sta }}$ is identified as the mean temperature variation averaged over a small centered area $(15 \mathrm{~mm} \times 10 \mathrm{~mm})$ on the specimen surface in the stabilized regime of temperature (Fig. 11). $\tau$ is a time constant characterizing local heat losses, it is estimated by calculating the slope of the temperature drop after stopping the vibrophore (at $t=t_{f}$ in Fig. 11). Fig. 11 shows an example of the evolution of $\theta_{d}$ over time experimentally measured by the infrared camera under the applied stress amplitude $\frac{\Delta \sigma}{2}=140 \mathrm{MPa}$, with the loading frequency, $f=87 \mathrm{~Hz}$, and the loading ratio, $R_{\sigma}=0.1$. For this example, $\tau=285 \mathrm{~s}$ and $\bar{\theta}_{d}^{\text {sta }}=14.7^{\circ} \mathrm{C}$. Therefore, according to Eq. (15), $d_{1}$ is estimated to be equal to $179.56 \mathrm{~kW} . \mathrm{m}^{-3}$ with an uncertainty of $0.85 \mathrm{~kW} . \mathrm{m}^{-3}$ mainly due to the thermal noise of the infrared camera $\left(\approx 0.07^{\circ} \mathrm{C}\right)$.

With the same method, the intrinsic dissipation, $d_{1}$, has been quantified for the different applied stress amplitudes. This enabled to plot the self-heating curve of C40 steel presented in Fig. 12, at $f=100 \mathrm{~Hz}$ and $R_{\sigma}=0.1$. It should be noted that the values of $d_{1}$ are determined at the same loading frequency, $f=100 \mathrm{~Hz}$, by using a linear dependence between the intrinsic dissipation and the loading frequency [4]. This actually has been done to plot the self-heating curve at the same loading frequency because the real loading frequency is not exactly the same at each applied stress amplitude during self-heating fatigue tests.

Now, in order to estimate the intrinsic dissipation due to microplasticity outside the RCPZ in the CCT specimen: first, the amplitude of

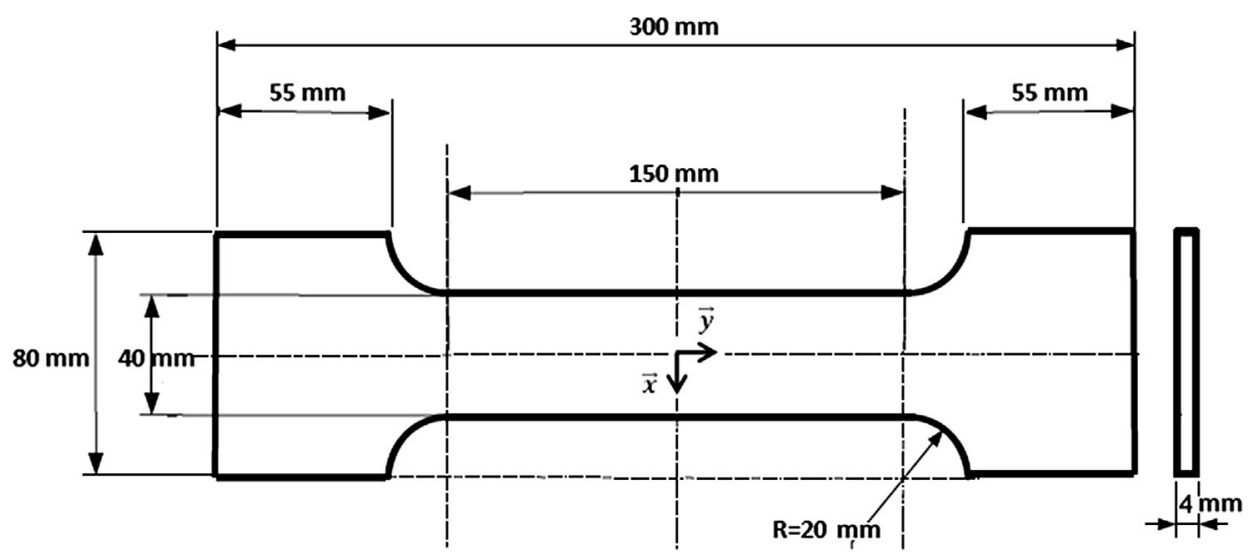

Fig. 9. Geometry of the non-cracked smooth specimens made of C40 steel and used for the self-heating fatigue tests. 


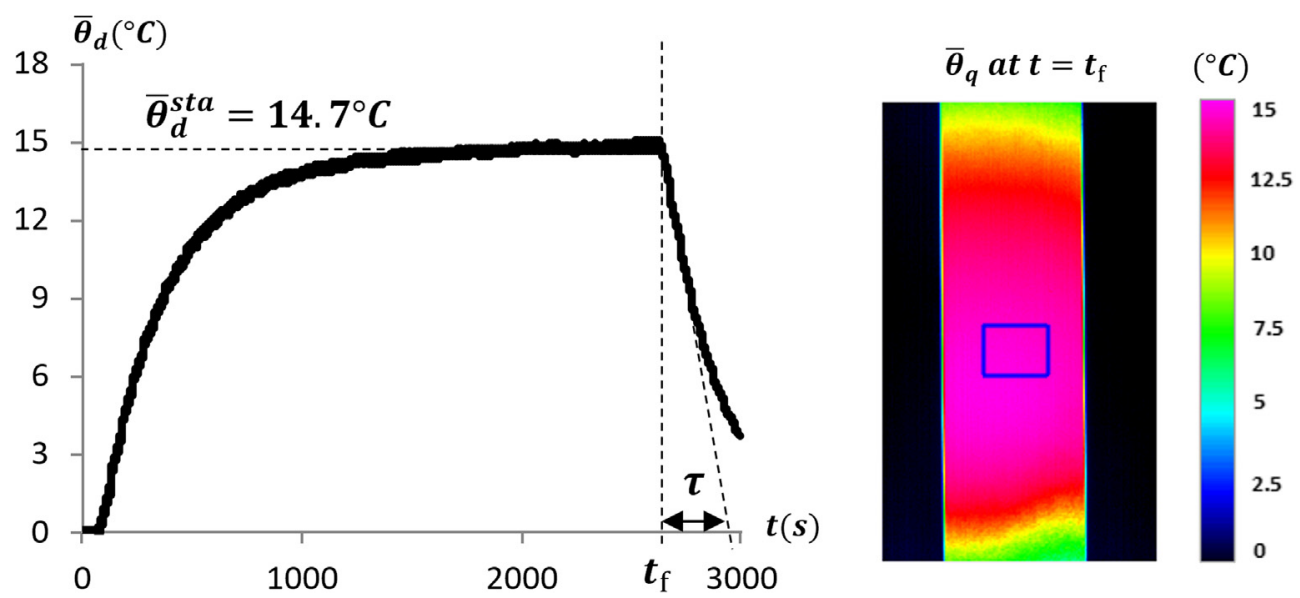

Fig. 11. Example of C40 steel self-heating measurement under the loading conditions $\frac{\Delta \sigma}{2}=140 \mathrm{MPa}, f=87 \mathrm{~Hz}$ and $R_{\sigma}=0.1$.

the Von Mises equivalent stress, $\sigma_{e q}(x, y)=\sqrt{\frac{3}{2} \overline{\bar{\sigma}}_{d}: \overline{\bar{\sigma}}_{d}(x, y)}$, where $\overline{\bar{\sigma}}_{d}(x, y)$ is the deviatoric part of the stress tensor, is computed by FEA in the quarter model of the CCT specimen subjected to a given normal stress amplitude. Indeed, when the CCT specimen is subjected to a normal stress amplitude, the stress response in the material is heterogeneous and multi-axial near the crack tip. Moreover, the intrinsic dissipation, $d_{1}$, is due to microplasticity outside the RCPZ. Thus, it is assumed that $d_{1}$ is linked to the Von Mises equivalent stress as usual plasticity criterion. Therefore, at each point outside the RCPZ in the CCT specimen, computing the value of $\sigma_{e q}$ allows to estimate the value of the associated $d_{1}$ by referring to the stress axis of the self-heating curve. This is done by assuming that outside the RCPZ, the load ratio is uniform and equal to the applied one $\left(R_{\sigma}=0.1\right)$.

Furthermore, it should be known that close to the RCPZ, the amplitude of the Von Mises equivalent stress is close to the cyclic yield stress $\left(\sigma_{y}^{c y c}=200 \mathrm{MPa}\right.$ for C40 steel), and then greater than the limit of the stress amplitude plotted in the self-heating curve $\left(\frac{\Delta \sigma}{2}=140 \mathrm{MPa}\right.$ in Fig. 12). Thus, the self-heating curve can be extrapolated by power law regression $\left(d_{1}=C(\Delta \sigma / 2)^{n}\right.$, with $C=2.51 E-4 \mathrm{~W} \cdot \mathrm{m}^{-3} \cdot \mathrm{MPa}^{-n}$ and $n=4.14)$ to approximate the values of $d_{1}$ for $\sigma_{e q} \leqslant 200 \mathrm{MPa}$. Fig. 12 depicts this extrapolation which remains rough and can be used as a first approximation providing an order of magnitude of the intrinsic

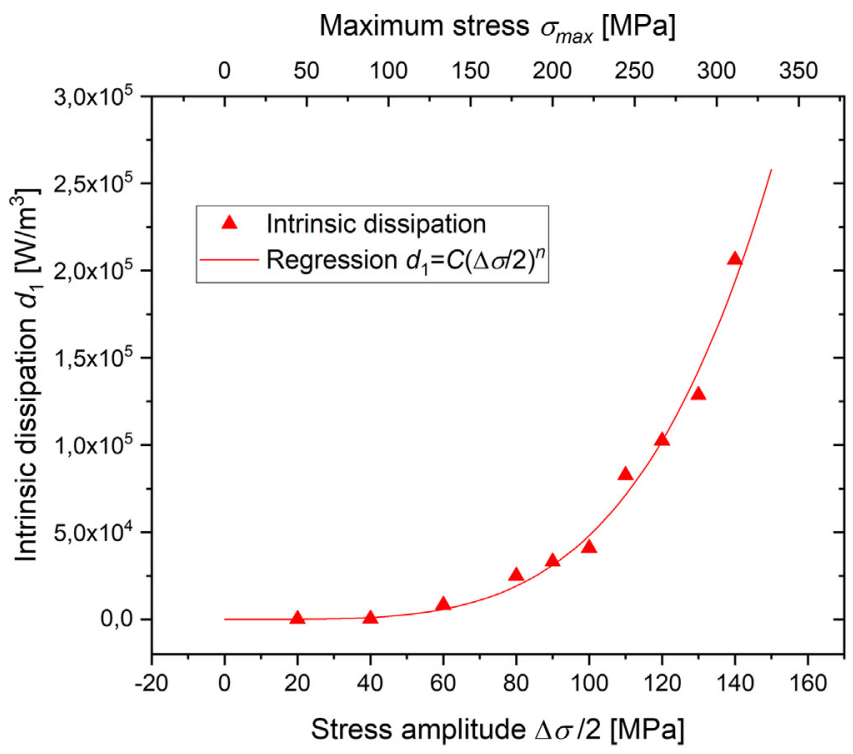

(a) dissipation, $d_{1}$, due to microplasticity close to the RCPZ. Inside the $\mathrm{RCPZ}$, the intrinsic dissipation due to microplasticity is supposed to be null.

Fig. 13 shows the field of the intrinsic dissipation due to microplasticity outside the RCPZ. The resulting temperature variation field, $\theta_{d}$, is computed by solving the associated heat-diffusion equation (Eq. (16)) in transient regime with the same assumptions and boundary conditions used to define the thermal problem of the thermoelastic source (Eq. (10)).

$\rho c \frac{\partial \theta_{d}}{\partial t}-k\left(\frac{\partial^{2} \theta_{d}}{\partial x^{2}}+\frac{\partial^{2} \theta_{d}}{\partial y^{2}}\right)+2 \frac{h}{e} \theta_{d}=d_{1}(x, y)$.

Fig. 14 depicts the temperature variation field, $\theta_{d}$, computed at the end of the loading configuration example considered before (Table 2), that is $t=258.4 \mathrm{~s}$. In the following, this temperature field, outside the $\mathrm{RCPZ}$, is used to compute the stress field, due to the part of thermal expansion resulting from the heat source $d_{1}$, which enables to calculate the associated thermal correction of the SIF.

\subsection{The cyclic plasticity dissipated into heat in the RCPZ}

The approach used in this work to estimate the cyclic plastic

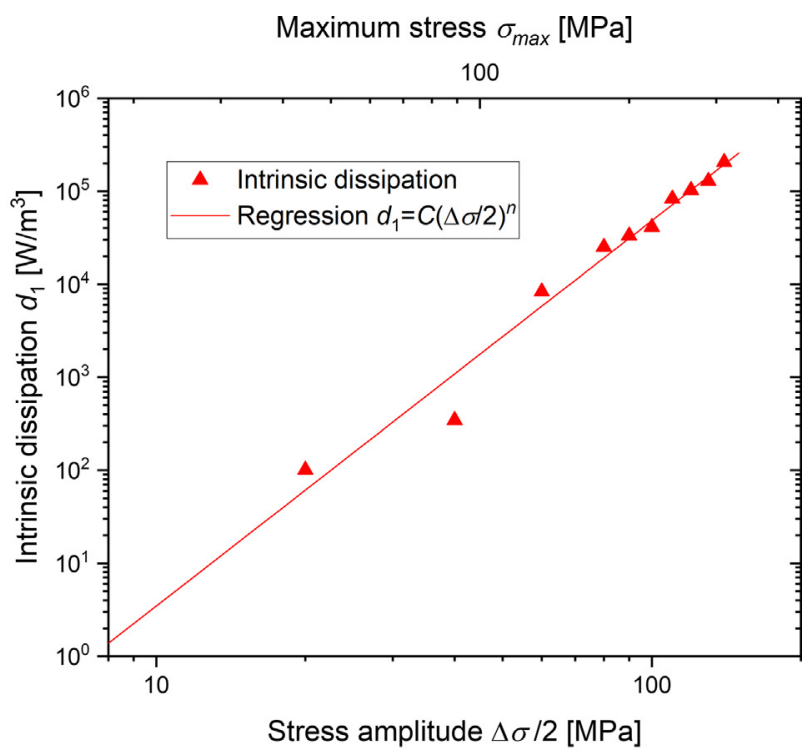

(b)

Fig. 12. Self-heating curve of C40 steel for $f=100 \mathrm{~Hz}$ and $R_{\sigma}=0.1$, (a) in linear scale and (b) in logarithmic scale. 


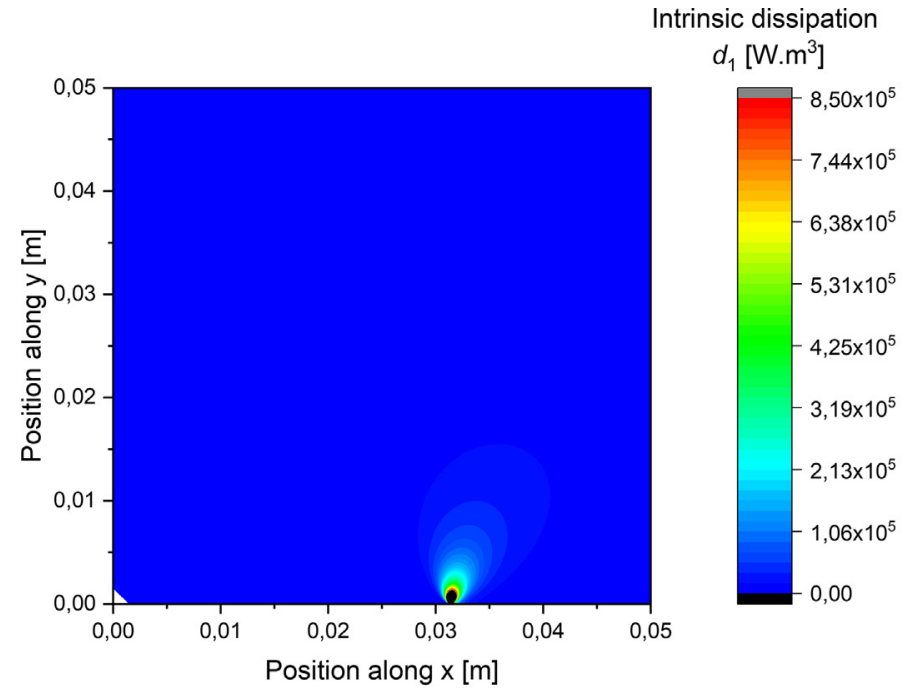

(a)

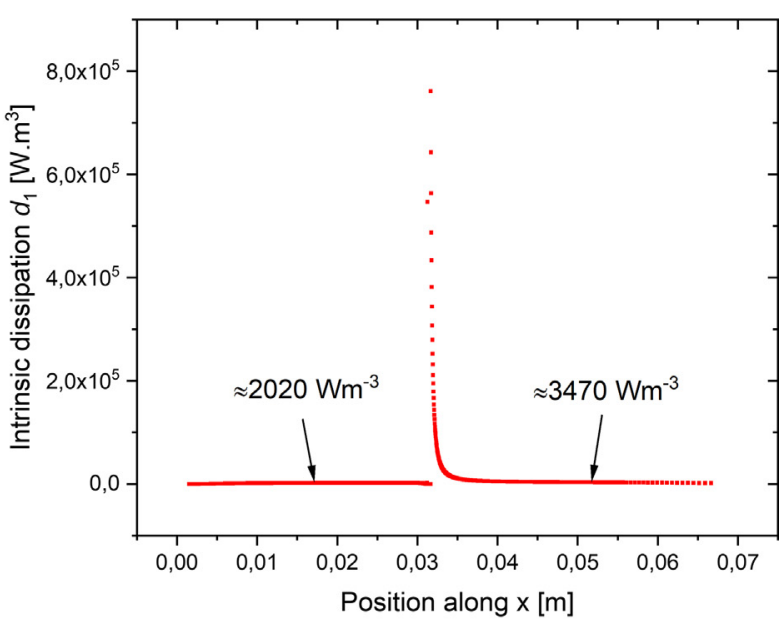

(b)

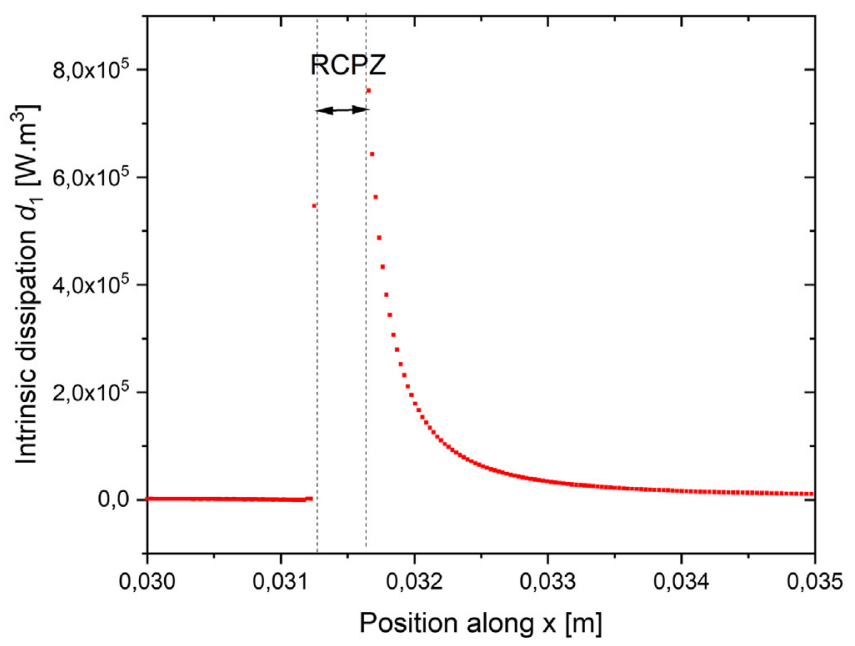

(c)


region, (b) evolution of $d_{1}$ along $x$ axis and (c) zoom near the RCPZ.

dissipation in heat, $q$, is described in [26]. The fatigue crack growth tests, with the loading conditions presented in Table 3 , have been carried out at room temperature (around $20^{\circ} \mathrm{C}$ ) by using the experimental devices consisting of the vibrophore as well as the IR camera presented in the previous section.

It should be mentioned that, in Table 3 , the test $T 4$ corresponds to the applied loading block considered before for highlighting the quantification of the heat sources, $s_{\text {the }}$, and $d_{1}$. Moreover, for simplification, it is assumed that the applied SIF range is constant and equal to the final applied one, $\Delta K_{I f}$, for each applied loading block. It should be mentioned that the applied load block $T 4$ is the limit, in terms of applied $\Delta K_{I}$, above which the condition of small scale yielding is violated.

During the tests, a high resolution optical camera was used to measure the initial and final lengths of the crack, $a_{i}$ and $a_{f}$ for each loading block. The lengths of the two cracks propagating from the central notch are very close (the maximum difference is less than $0.5 \mathrm{~mm}$ ), thus only the results of one crack side are reported in the following for the estimation of the heat source $q$.

Based on the linearity of the corresponding heat diffusion problem, the heat source $q$ can be estimated by Eq. (17) by assuming a spot heat source model located at the center of the disc modeling the RCPZ: $q=\frac{\bar{\theta}_{q}^{e x p}}{\bar{\theta}_{q_{1}}} q_{1}$

where $q_{1}$ is the unit heat source $\left(q_{1}=1 \mathrm{~W} . \mathrm{m}^{-1}\right), \bar{\theta}_{q}^{\exp }$ is the total increase, between the beginning and the end of the applied loading block, of the average temperature variation measured by the infrared camera in a small area named Area A $(1.6 \mathrm{~mm} \times 1.6 \mathrm{~mm})$ outside the RCPZ, as shown in Fig. 15. $\bar{\theta}_{q_{1}}$ is the total increase of the temperature variation calculated by FEA for $q=q_{1}=1 \mathrm{~W} . \mathrm{m}^{-1}$ in Area A.

Fig. 15 shows the infrared measurements under the applied loading block T4 (Table 3). The temperature field map (a) of Fig. 15 corresponds to the end of the loading block $\left(t=t_{f}\right)$, it shows a heterogeneous temperature field at the crack tip. The temperature oscillations appearing in the curve (b) of Fig. 15 are due to the thermo-elastic effect. The average temperature variation, $\bar{\theta}^{\exp }$, is due to both the cyclic plastic dissipation in heat and the intrinsic dissipation due to microplasticity outside the RCPZ. It is plotted by averaging the oscillating curve over a time series of $20 \mathrm{~s}$. To obtain only the contribution of the cyclic plasticity occurring in the RCPZ, the temperature variation due to microplasticity in area A, calculated in the previous section $\left(0.32{ }^{\circ} \mathrm{C}\right.$ on Fig. 14) is subtracted. Indeed, the temperature increase measured in area A (Fig. 15a) is assumed to be due only to the heat produced by 




(a)

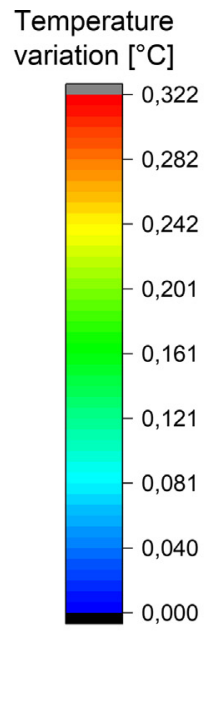

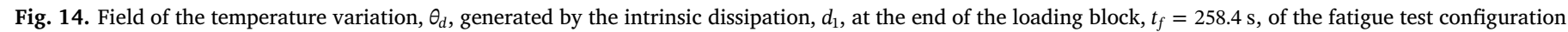
T4: $a_{f}=29.8 \mathrm{~mm}, \Delta K_{I_{f}}=28.0 \mathrm{MPa} . \sqrt{\mathrm{m}}, R_{K}=0.1$, and $f=98.6 \mathrm{~Hz}$, (a) Zoom near the crack tip region, and (b) evolution of $\theta_{d}$ along $x$-axis.

Table 3

Experimental conditions of the fatigue crack growth tests at $R_{K}=0.1$.

\begin{tabular}{lllllll}
\hline Test & $f(\mathrm{~Hz})$ & $a_{i}(\mathrm{~mm})$ & $\Delta K_{I_{i}}(\mathrm{MPa} . \sqrt{\mathrm{m}})$ & $a_{f}(\mathrm{~mm})$ & $\Delta K_{I_{f}}(\mathrm{MPa} . \sqrt{\mathrm{m}})$ & $N($ cycle $)$ \\
\hline$T 1$ & 100 & 15.3 & 16 & 16.9 & 16.7 & 40500 \\
$T 2$ & 99.5 & 16.9 & 20 & 19.3 & 21.3 & 21000 \\
$T 3$ & 99 & 22.3 & 23 & 25.6 & 24.5 & 31000 \\
$T 4$ & 98.6 & 25.6 & 26 & 29.8 & 28.0 & 25500 \\
\hline
\end{tabular}

cyclic plasticity occurring in the RCPZ. For this example, the experimental temperature increment in area $\mathrm{A}$ is $\bar{\theta}^{\overline{e x p}}=0.97^{\circ} \mathrm{C}$ and thus the contribution of the cyclic plasticity in the RCPZ only is $\bar{\theta}_{q}^{\exp }=0.65^{\circ} \mathrm{C}$. A linear heat source $q=42.2 \mathrm{~W} . \mathrm{m}^{-1}$ can also be calculated with Eq. (17) using the temperature increment in area $\mathrm{A}$ for a unit heat source $\bar{\theta}_{q_{1}}=0.0154{ }^{\circ} \mathrm{C}$.

It must be noted that the optical performance of the infrared camera does not allow to correctly measure the temperature close to the RCPZ, that is why the temperature variation field, $\theta_{q}$, generated by the heat source, $q$, is numerically computed by solving the associated heat diffusion equation in transient regime (Eq. (18)).

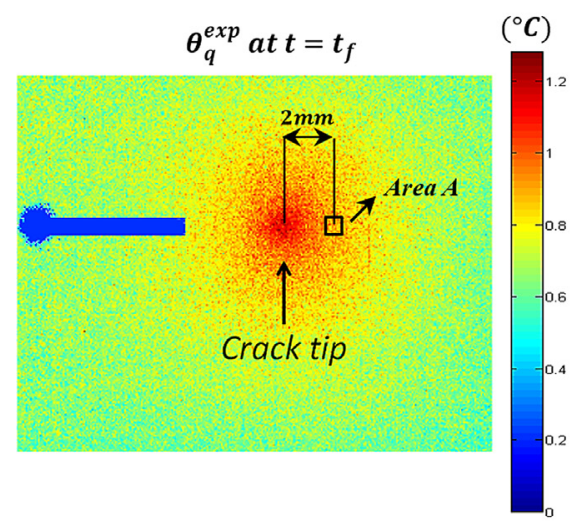

$\rho c \frac{\partial \theta_{q}}{\partial t}-k\left(\frac{\partial^{2} \theta_{q}}{\partial x^{2}}+\frac{\partial^{2} \theta_{q}}{\partial y^{2}}\right)+2 \frac{h}{e} \theta_{q}=q \delta(0)$

with the same thermal boundary conditions as those presented in the thermal problem with the thermoelastic source (Section 4.1).

For instance, by considering the loading configuration used in the two previous sections to compute the temperature variation fields, $\theta_{\text {the }}$, and $\theta_{d}$, namely: $a_{f}=29.8 \mathrm{~mm}, \Delta K_{I_{f}}=28.0 \mathrm{MPa} . \sqrt{\mathrm{m}}, R_{K}=0.1$, and $f=98.6 \mathrm{~Hz}$, which actually corresponds to the configuration of the applied load block referenced by $T 4$ (Table 3), the temperature variation field, $\theta_{q}$, is computed with the associated dissipated power per unit length of the crack front, $q=42.2 \mathrm{~W} . \mathrm{m}^{-1}$. Fig. 16 depicts the distribution of the temperature variation field, $\theta_{q}$, computed at $t=258.4 \mathrm{~s}$ which is the time of the end of cyclic loading.

In Fig. 16, the peak of the temperature variation, $\theta_{q}$, is reached at the crack tip region because of the singularity due to the spot heat source $q$ applied at the center of the disc modeling the RCPZ. Modeling the heat source located in the RCPZ as a spot source was validated in [26].

\section{Computing the thermal corrections of the SIF}

As explained in the methodology presented in Section 2, solving the

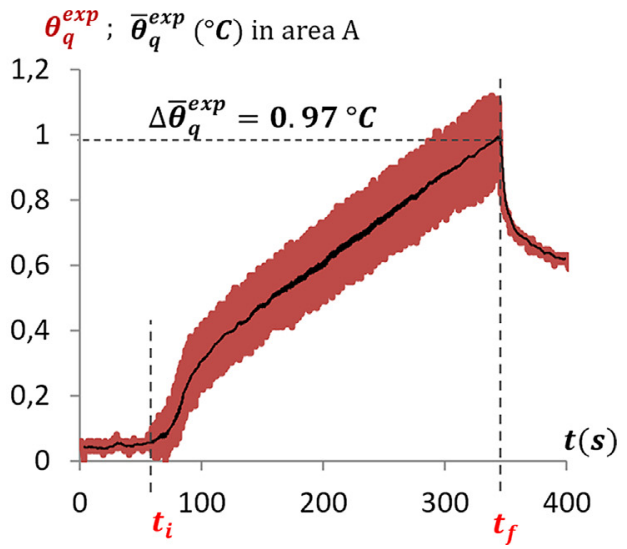

Fig. 15. (a) Infrared measurement of the temperature variation field, $\theta_{q}^{e x p}$, at $t=t_{f}$ under the conditions of the loading block $T 4$, (b) Evolution over time of $\theta_{q}^{e x p}$ and $\bar{\theta}_{q}^{\exp }$, spatially averaged in Area A, during the whole applied loading block. 
Temperature variation field $\left[{ }^{\circ} \mathrm{C}\right]$

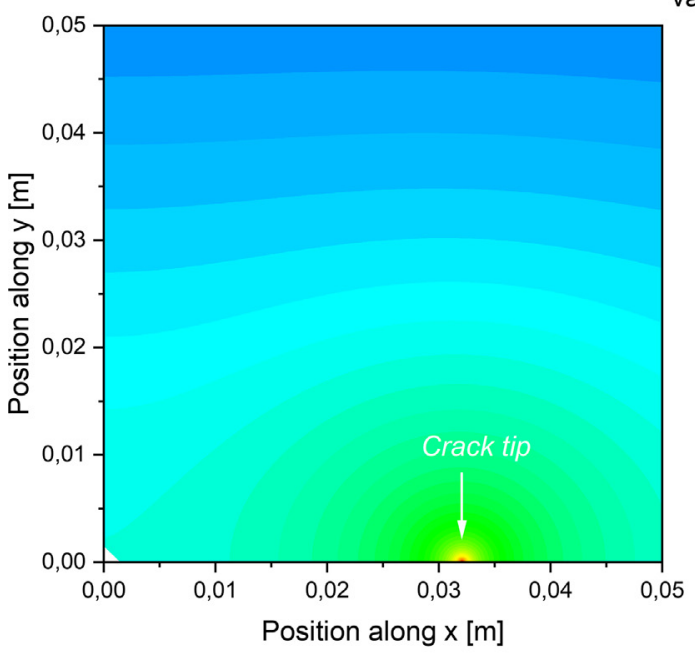

(a)

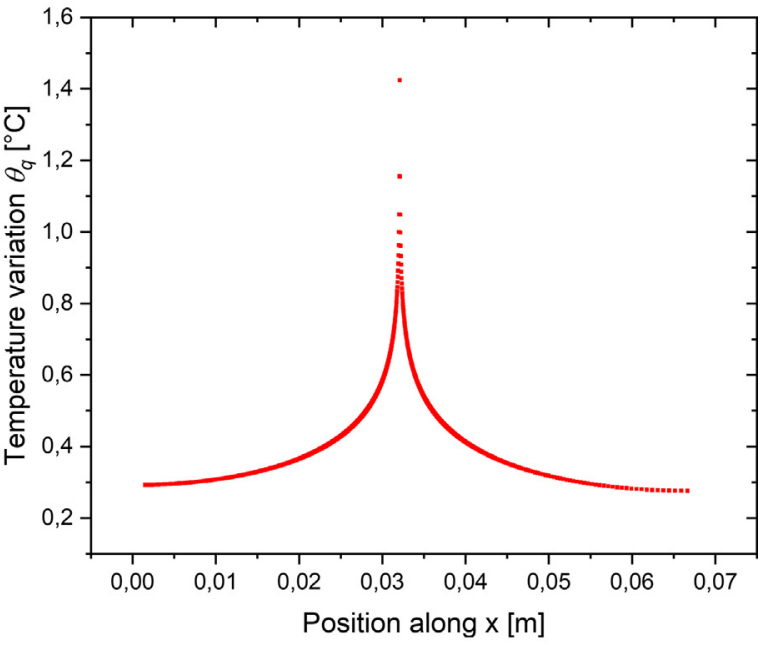

(b)


$t_{f}=258.4 \mathrm{~s}: a_{f}=29.8 \mathrm{~mm}, \Delta K_{I_{f}}=28.0 \mathrm{MPa} . \sqrt{\mathrm{m}}, R_{K}=0.1$, and $f=98.6 \mathrm{~Hz}$.

thermomechanical problem of the uncracked sub-problem (Fig. 3) consists in computing the normal stress fields, $\sigma_{y y}^{\text {the }}, \sigma_{y y}^{d}$, and $\sigma_{y y}^{q}$, respectively generated by the thermal expansion due to the temperature variation fields, $\theta_{\text {the }}, \theta_{d}$, and $\theta_{q}$. These stress fields lead afterward to compute the associated thermal corrections of the SIF.

It should be mentioned that $\sigma_{y y}^{\text {the }}$ is in phase with $\theta_{\text {the }}$ according to the classic linear thermo-elasticity, and is out of phase with the material stress response due to the mechanical cyclic loading. $\sigma_{y y}^{\text {the }}$ can be written as:

$\sigma_{y y}^{\text {the }}(x, y, t)=\sigma_{a}^{\text {the }}(x, y) \sin (2 \pi f t+\varphi(x, y))$

Fig. 17 shows the evolution over the crack axis of $\sigma_{a}^{\text {the }}$, the amplitude of the normal stress field related to the thermo-elastic effect, as well as the evolution of $\sigma_{y y}^{d}$ and $\sigma_{y y}^{q}$ computed at the end of the fatigue crack growth test $T 4$ (at $t_{f}=258.4 \mathrm{~s}$ ) considered as a loading configuration example to highlight the numerical calculations. It can be observed that the three normal stress fields are strongly heterogeneous and compressive near the RCPZ.

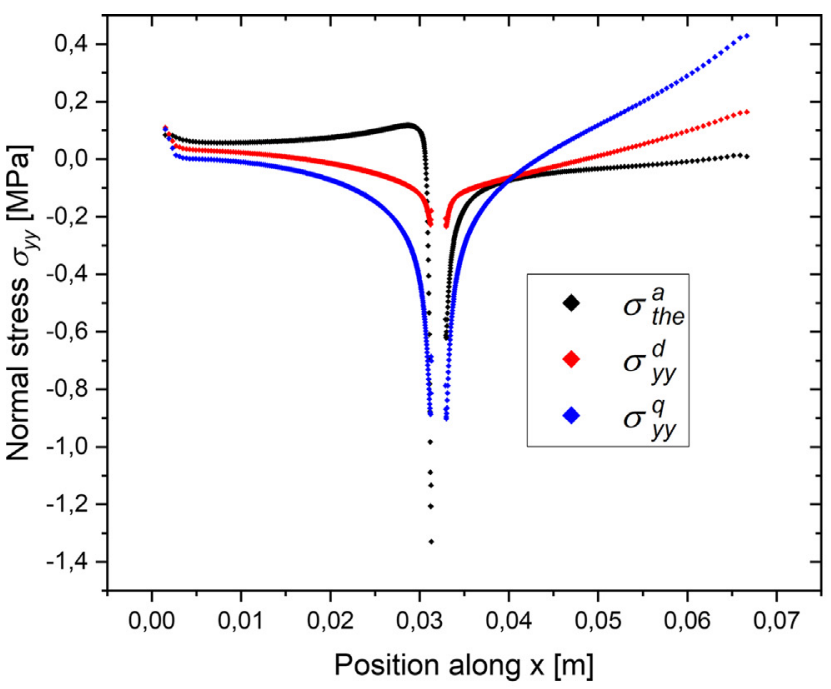

(a)
The SIF thermal correction due to the thermo-elastic source, $s_{\text {the }}$, is denoted by $K_{I_{t h}}^{\text {the }}(t)$. According to Eq. (5), $K_{I_{t h}}^{\text {the }}(t)$ can be written as:

$K_{I_{t h}}^{\text {the }}(t)=2 \sqrt{\frac{a}{\pi}} \int_{r}^{a+r} \frac{\sigma_{y y}^{\text {the }}(x, t)}{\sqrt{a^{2}-(x-r)^{2}}} \mathrm{~d} x$,

Since $\sigma_{y y}^{\text {the }}(x, t)$ is sinusoidal, Eq. (20) can be rewritten as follows:

$K_{I_{t h}}^{\text {the }}(t)=\frac{\Delta K_{I_{t h}}^{\text {the }}}{2} \sin (2 \pi f t+\phi)$,

such that:

$\frac{\Delta K_{I t h}^{\text {the }}}{2}=2 \sqrt{\frac{a}{\pi}}\left|\int_{r}^{a+r} \frac{\sigma_{t h e}^{a}(x) \cdot e^{j \varphi(x)}}{\sqrt{a^{2}-(x-r)^{2}}} \mathrm{~d} x\right|$

and

$\phi=\arg \left(\int_{r}^{a+r} \frac{\sigma_{t h e}^{a}(x) \mathrm{e}^{j(\varphi(x))}}{\sqrt{a^{2}-(x-r)^{2}}} \mathrm{~d} x\right)$,

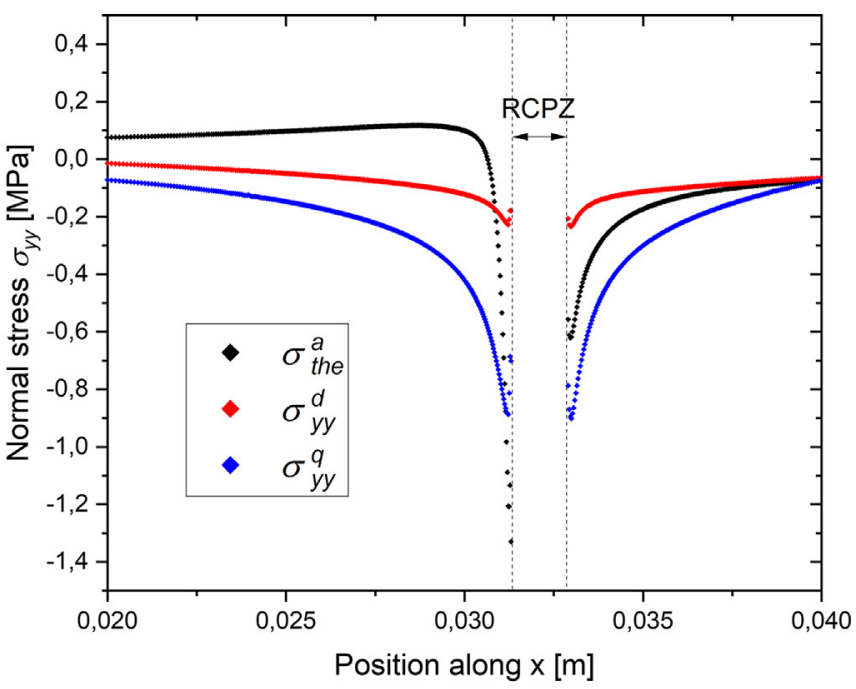

(b)

Fig. 17. (a) Normal stress fields $\sigma_{a}^{\text {the }}, \sigma_{y y}^{d}\left(t_{f}\right)$ and $\sigma_{y y}^{q}\left(t_{f}\right)$, along the cracked axis, at the end of the fatigue test $T 4\left(t_{f}=258.4 \mathrm{~s}, c f\right.$. Table 3 ), (b) zoom on the RCPZ. 
Table 4

Relative corrections on the $R_{K}$-ratio near the crack tip resulting from the effects of the three types of heat sources.

\begin{tabular}{ccccccc}
\hline Test & $R_{K}$ & $\begin{array}{c}\Delta K_{I_{f}} \\
(\mathrm{MPa} . \sqrt{\mathrm{m}})\end{array}$ & $\begin{array}{c}\chi_{R}\left\{s_{\text {the }}\right\} \\
(\%)\end{array}$ & $\begin{array}{c}\chi_{R}\left\{d_{1}\right\} \\
(\%)\end{array}$ & $\begin{array}{c}\chi_{R}\{q\} \\
(\%)\end{array}$ & $\begin{array}{c}\chi_{R}\left\{s_{\text {the }}+d_{1}+q\right\} \\
(\%)\end{array}$ \\
\hline$T 1$ & 0.1 & 16.7 & -1.28 & -0.11 & -1.20 & 2.59 \\
$T 2$ & 0.1 & 21.3 & -1.31 & -0.18 & -1.62 & 3.11 \\
$T 3$ & 0.1 & 24.5 & -1.35 & -0.29 & -1.42 & 3.06 \\
$T 4$ & 0.1 & 28.0 & -1.41 & -0.39 & -1.72 & 3.52 \\
\hline
\end{tabular}

where $\frac{\Delta K_{I_{t h}}^{t h e}}{2}$ is the amplitude of $K_{I_{t h}}^{\text {the }}(t), j$ the imaginary unit and $\phi$ is the phase shift between $K_{I_{t h}}^{\text {the }}(t)$ and the SIF associated with the mechanical response, $K_{I}(t)$.

As a consequence, the thermoelastic coupling effect on the SIF can be expressed as follows:

$$
\begin{aligned}
K_{I}^{\text {corr,the }}(t) & =K_{I}(t)+K_{I_{t h}}^{\text {the }}(t), \\
& =\frac{\Delta K_{I}}{2} \sin (2 \pi f t)+K_{I}^{m}+\frac{\Delta K_{I_{t h}}^{\text {the }}}{2} \sin (2 \pi f t+\phi),
\end{aligned}
$$

where $K_{I}^{\text {corr,the }}$ is the SIF corrected by taking into account the thermoelastic coupling effect only. Simplifying this sinusoidal sum leads to write, $K_{I}^{\text {corr,the }}$, as:

$K_{I}^{\text {corr the }}(t)=\frac{\Delta K_{I}^{\text {corr }, \text { the }}}{2} \sin (2 \pi f t+\psi)+K_{I}^{m}$,

where $\Delta K_{I}^{\text {corr,the }}$ is the SIF range corrected by taking into account the thermoelastic effect, and $\psi$ its phase shift, both explicitly expressed as follows:

$\frac{\Delta K_{I}^{\text {corr the }}}{2}=\left|\frac{\Delta K_{I}}{2}+\frac{\Delta K_{I_{t h}}^{\text {the }}}{2} \mathrm{e}^{j \phi}\right|$

and

$\psi=\arg \left(\frac{\Delta K_{I}}{2}+\frac{\Delta K_{I_{t h}}^{t h e}}{2} \mathrm{e}^{j \phi}\right)$.

Numerically, at the end of the loading block of the test T4, that gives: $\Delta K_{I_{f}}^{\text {corr } \text { the }}=28.08 \mathrm{MPa} . \sqrt{\mathrm{m}}$. As a result, in comparison with the applied SIF range $\left(\Delta K_{I_{f}}=28.0 \mathrm{MPa} . \sqrt{\mathrm{m}}\right)$, the correction is about $0.29 \%$, and will be considered negligible.

On the other hand, the normal stress field, $\sigma_{y y}^{d}(t=258.4 \mathrm{~s})$, due to the effect of the intrinsic dissipation related to microplasticity outside the RCPZ, enables to calculate the associated thermal correction on the SIF: $K_{I_{t h}}^{d}(t=258.4 \mathrm{~s})=-0.0136 \mathrm{MPa} . \sqrt{\mathrm{m}}$. It is negative because of the compressive stress field due to the part of the thermal expansion induced by the heat source, $d_{1}$. Let us recall that to simplify the analysis, $K_{I_{t h}}^{d}$ is assumed to be time-independent during the duration of the applied loading block.

In the same context, the normal stress field, $\sigma_{y y}^{q}(t=258.4 \mathrm{~s})$, generated by the thermal expansion due to the cyclic plasticity dissipated into heat, $q$, leads to compute the associated thermal correction on the SIF: $K_{I_{t h}}^{q}(t=258.4 \mathrm{~s})=-0.0592 \mathrm{MPa} . \sqrt{\mathrm{m}}$, which can also be assumed constant during one applied loading block for simplification.

The effects of the dissipative sources, $d_{1}$, and $q$, on the SIF, $K_{I}(t)$, can be written as:

$$
\begin{aligned}
K_{I}^{\text {corr }, d+q}(t) & =K_{I}(t)+K_{I_{t h}}^{d}+K_{I_{t h}}^{q}, \\
= & \frac{\Delta K_{I}}{2} \sin (2 \pi f t)+K_{I}^{m}+K_{I_{t h}}^{d}+K_{I_{t h}}^{q} .
\end{aligned}
$$

Thus, according to Eq. (30), since the thermal corrections, $K_{I t h}^{d}$, and $K_{I t h}^{q}$, are both negative, the heat sources $d_{1}$, and $q$, contribute to decrease the value of the mean SIF, $K_{I}^{m}$ (for this loading configuration example, $K_{I}^{m}=17.11 \mathrm{MPa} . \sqrt{\mathrm{m}}$ ). However, this decrease is small, particularly that associated with the heat source, $d_{1}$. Moreover, the two dissipative sources do not affect the SIF range.

In terms of correction on the $R_{K}$-ratio, let $\chi_{R_{K}}$ be the relative correction associated with the $R_{K}$-ratio near the crack tip, such that:

$\chi_{R_{K}}=\frac{R_{K}^{c o r r}, *-R_{K}}{R_{K}}$,

where $R_{K}^{c o r r * *}$ is the corrected $R_{K}$-ratio calculated for each heat source:

- For the thermoelastic source, $s_{\text {the }}$, and according to Eq. (26):

$$
R_{K}^{\text {corr, the }}=\frac{K_{I_{\min }^{\text {corr } \text { the }}}^{\text {corr,the }}}{K_{I_{\max }}^{\text {cor }}}=\frac{-\frac{\Delta K_{I}^{\text {corr }, \text { the }}}{2}+K_{I}^{m}}{\frac{\Delta K_{I}^{\text {corr,the }}}{2}+K_{I}^{m}} .
$$

- For the intrinsic dissipation due to microplasticity, $d_{1}$, and according to Eq. (30):

$$
R_{K}^{c o r r, d}=\frac{K_{I_{\min }}^{\text {corr }, d}}{K_{I_{\max }}^{\text {corr }, d}}=\frac{-\frac{\Delta K_{I}}{2}+K_{I}^{m}+K_{I_{t h}}^{d}}{\frac{\Delta K_{I}}{2}+K_{I}^{m}+K_{I_{t h}}^{d}},
$$

- For the heat source, $q$, and according to Eq. (30):

$$
R_{K}^{\text {corr }, q}=\frac{K_{I_{\min }}^{\text {corr }, q}}{K_{I_{\max }}^{\text {corr }, q}}=\frac{-\frac{\Delta K_{I}}{2}+K_{I}^{m}+K_{I_{t h}}^{q} .}{\frac{\Delta K_{I}}{2}+K_{I}^{m}+K_{I_{t h}}^{q}} .
$$

Table 4 summarizes the numerical calculation of the relative corrections, $\chi_{R}$, due to each heat source at the end of the four tests.

As it can be seen in Table 4, the three heat sources tend to decrease the initial value of the $R_{K}$-ratio. Moreover, the cyclic plasticity dissipated into heat in the RCPZ generates a relatively greater effect on $R_{K}$ compared to the intrinsic dissipation but similar to the effect due to thermoelasticity.

Now, by considering the total effect of the three heat sources on the SIF, the corrected $R_{K}$-ratio near the crack tip would be:

$$
\begin{aligned}
R_{K}^{\text {corr }}= & \frac{K_{I_{\min }}^{\text {corr }}}{K_{I_{\max }}^{\text {corr }}}, \\
& =\frac{-\frac{\Delta K_{I}^{\text {corr }, \text { the }}}{2}+K_{I}^{m}+K_{I_{t h}}^{d}+K_{I_{t h}}^{q}}{\frac{\Delta K_{I}^{\text {corr }, \text { the }}}{2}+K_{I}^{m}+K_{I_{t h}}^{d}+K_{I_{t h}}^{q}} .
\end{aligned}
$$

Table 4 presents the numerical results of $R_{K}^{\text {corr }}$. As a result, considering the total effect of the three heat sources, $s_{\text {the }}, d_{1}$, and $q$, increases the consequences on the $R_{K}$-ratio representing the local loading ratio at the crack tip.

\section{Conclusion and prospects}

In this study, the thermal effects on the SIF generated during mode I cyclic loading of a CCT specimen, made of C40 steel, have been separately studied according to the LEFM hypothesis. The thermal effects in question are related to the heat sources associated with the thermoelastic coupling, the intrinsic dissipation due to microplasticity outside the RCPZ, and the cyclic plasticity dissipated into heat in the RCPZ ahead of the crack tip. Each heat source creates a heterogeneous temperature field at the crack tip which induces a heterogeneous stress field by thermal expansion of the material. As a consequence, the SIF is modified. For C40 steel, under an applied load ratio, $R_{\sigma}=0.1$, at loading frequencies around $100 \mathrm{~Hz}$, and applied SIF ranges, $16.7 \mathrm{MPa} . \sqrt{\mathrm{m}} \leqslant \Delta K_{I} \leqslant 28.0 \mathrm{MPa}$. $\sqrt{\mathrm{m}}$ fulfilling the small scale yielding condition, the consequences on the SIF are small. Despite this result, now it is known that the thermoelastic source modifies the SIF range by 
increasing its initial value, while the intrinsic dissipation due to microplasticity outside the RCPZ, and the cyclic plasticity dissipated into heat in the RCPZ, both do not modify the SIF range, but decrease the mean value of the SIF. Even though the three types of heat sources modify the $R$-ratio by decreasing its initial value, the effect related to the cyclic plasticity dissipated into heat in the RCPZ is closed to the effect of the thermoelastic coupling and higher than the effect of intrinsic dissipation in our experimental conditions.

The thermal corrections on the SIF and $R_{K}$-ratio are relatively low according to the loading conditions presented in this paper for a loading frequency of about $100 \mathrm{~Hz}$. But it has to be reminded that the heat sources depend on the applied load, which means that these thermal effects could generate important consequences on the SIF if the applied loading parameters, particularly the loading frequency, $f$, and the applied SIF range, $\Delta K_{I}$, were high. As an example, if the loading frequency increases from $500 \mathrm{~Hz}$ or to $1000 \mathrm{~Hz}$ the thermal correction will respectively reach $15 \%$ and $30 \%$. For the ultrasonic tests at a frequency of $20 \mathrm{kHz}$ an extrapolation of the model would give a thermal correction of $600 \%$ which will be probably an over estimation of the thermal effect due to the invalidity of model hypothesis. That is why additional work is ongoing to study the effect of the loading frequency, specially at very high frequencies in the range of kilo-Hz used in ultrasonic fatigue tests, where the thermal effects are amplified and consequently could have more impact on the SIF.

\section{Author statement}

Category 1. Conception and design of study: Z. Boussattine, N. Ranc, T. Palin-Luc. Acquisition of data: Z. Boussattine, N. Ranc, T. Palin-Luc. Analysis and/or interpretation of data: Z. Boussattine, N. Ranc, T. Palin-Luc.

Catergory 2. Drafting the manuscript: Z. Boussattine, N. Ranc, T. Palin-Luc. Revising the manuscript critically for intellectual content: $\mathrm{Z}$. Boussattine, N. Ranc, T. Palin-Luc.

Category 3. Approval of the version of the manuscript to be published (the names of all authors must be listed): Z. Boussattine, N. Ranc, T. Palin-Luc.

\section{Declaration of Competing Interest}

The authors declare that they have no known competing financial interests or personal relationships that could have appeared to influence the work reported in this paper.

\section{References}

[1] ASTM-E647, Standard test method for measurement of fatigue crack growth rates, Standard ASTM E647 - 13e1, 2013.

[2] R. Attermo, G. Östberg, Measurements of the temperature rise ahead of a fatigue crack, Int. J. Fract.Mech. 7 (1971).

[3] G.I. Barenblatt, Mathematical theory of equilibrium cracks in brittle fracture, Adv. Appl. Mech. 7 (1962) 55.

[4] B. Berthel, B. Wattrisse, A. Chrysochoos, A. Galtier, Thermographic analysis of fatigue dissipation properties of steel sheets, in: International Conference on
Photomechanics, vol. 43, 2007, pp. 273-279.

[5] T. Boulanger, A. Chrysochoos, C. Mabru, A. Galtier, Calorimetric analysis of dissipative and thermoelastic effects associated with the fatigue behavior of steels, Int. J. Fatigue 26 (2004) 221-229.

[6] H.F. Bueckner, A novel principle for the coputation of stress intensity factors, ZAMM 50 (1970) 529-545.

[7] D.J. Cartwright, D.P. Rooke, Green's functions in fracture mechanics, Royal Aircraft Establishment, Technical Report 80035, 1980.

[8] G. Cherepanov, Crack propagation in continuous media: Pmm, 31(3) (1967) 476-488. J. Appl. Mathe. Mech. 31 (1967) 503-512.

[9] A. Chrysochoos, H. Louche, An infrared image processing to analyse the calorific effects accompanying strain localisation, Int. J. Eng. Sci. 38 (2000) 1759-1788.

[10] J.M.C. Duhamel, Second mémoire sur les phénomènes thermo-mécaniques, J. l'Ecole Polytechnique, France, cahier 25 (15) (1837) 1-57.

[11] W. Farren, G. Taylor, The heat developed during plastic extension of metals, Proc. Roy. Soc. A (1925) 422-451.

[12] C.E. Feddersen, Discussion to plane strain crack toughness testing, ASTM, Special Technical Publication, No. 410, 77, 1966.

[13] G.R. Irwin, Analysis of stresses and strains near the end of a crack transversing a plate, J. Appl. Mech. 24 (1957) 361-364.

[14] G.R. Irwin, Plastic zone near a crack tip and fracture toughness, Sagamore Ordnance Mater. Conf. 4 (1960) 63-78.

[15] R. Jones, S. Pitt, An experimental evaluation of crack face energy dissipation, Int. J. Fatigue 28 (2006) 1716-1724.

[16] A.S. Kobayashi, R.D. Cherepy, W.C. Kinsel, A numerical procedure for estimating the stress intensity factors of a crack in a finite plate, J. Basic Eng. 86 (1964) 681

[17] W.T. Koiter, Note on the stress intensity factor for sheet strips with cracks under tensile loads, Report No. 314, University of Technology, Laboratory of Engineering Mechanics, Delft, Netherlands, 1965.

[18] G. La Rosa, A. Risitano, Thermographic methodology for rapid determination of the fatigue limit of materials and mechanical components, Int. J. Fatigue 22 (2000) 65-73.

[19] J. Lemaitre, J. Chaboche, Mechanics of Solid Materials, Cambridge University Press, 1990.

[20] H. Louche, Analyse par thermographie infrarouge des effets dissipatifs de la localisation dans des aciers, Thèse de Doctorat, Université Montpellier 1, France, 1999.

[21] M.P. Luong, Infrared thermographic scanning of fatigue in metals, Nucl. Eng. Des. 158 (1995) 363-376.

[22] G. Meneghetti, M. Ricotta, A heat energy dissipation approach to elastic-plastic fatigue crack propagation, Theoret. Appl. Fract. Mech. 105 (2020) 102405.

[23] P.C. Paris, The mechanics of fracture propagation and solutions to fracture arrester problems, Document D2-2195, The Boeing Company, 1957.

[24] R. Pippan, H.P. Stüwe, Thermische bestimmung der plastischen deformation um die rissfront eines ermüdungsbruches, Zeitschrift für Metalkunde (1983) 699-704.

[25] N. Ranc, T. Palin-Luc, P. Paris, Thermal effect of plastic dissipation at the crack tip on the stress intensity factor under cyclic loading, Eng. Fract. Mech. 78 (2011) 961-972.

[26] N. Ranc, T. Palin-Luc, P. Paris, N. Saintier, About the effect of plastic dissipation in heat at the crack tip on the stress intensity factor under cyclic loading, Int. J. Fatigue 58 (2014) 56-65.

[27] J.R. Rice, Plastic yielding at a crack tip, 1st International Conference on Fracture, Sendai, Japan, 1965, pp. 283-308.

[28] J.R. Rice, Fatigue Crack Propagation. The mechanics of crack tip deformation and extension by fatigue, ASTM Special Technical Publication 415. Philadelphia, 1967.

[29] J.R. Rice, A path independent integral and the approximate analysis of strain concentration by notches and cracks, J. Appl. Mech. 35 (1968) 379-386.

[30] J.R. Rice, Some remarks on elastic crack-tip stress fields, Int. J. Solids Struct. 8 (1972) 751-758.

[31] J.L. Swedlow, Surface Crack: Physical Problems and Computational Solutions, ASME, New York, 1972.

[32] H. Tada, P.C. Paris, G.R. Irwin, The Stress Analysis of Cracks Handbook, 1st ed., Del Research Corporation, Hellertown, PA, 1973.

[33] G. Taylor, H. Quinney, The latent energy remaining in a metal after cold working, Proc. Roy. Soc. A (1934) 307-326.

[34] W. Thomson, On the thermoelastic, thermomagnetic and pyro-electric properties of matter, Phil. Mag. 5 (1878) 4-27.

[35] H.M. Westergaard, Bearing pressures and cracks, J. Appl. Mech. 6 (1939) 49-53. 